This manuscript has been authored by UT-Battelle, LLC under Contract No. DE-AC05-00OR22725 with the U.S. Department of Energy. The United States Government retains and the publisher, by accepting the article for publication, acknowledges that the United States Government retains a non-exclusive, paid-up, irrevocable, world-wide license to publish or reproduce the published form of this manuscript, or allow others to do so, for United States Government purposes. The Department of Energy will provide public access to these results of federally sponsored research in accordance with the DOE Public Access Plan (http://energy.gov/downloads/doe-public-access-plan). 


\title{
Thermal activation mechanisms and Labusch-type strengthening analysis for a family of high-entropy and equiatomic solid-solution alloys
}

\author{
Zhenggang $\mathrm{Wu},{ }^{1}$ Yanfei Gao, ${ }^{1,2,{ }^{*}}$ Hongbin $\mathrm{Bei}^{2, *}$ \\ ${ }^{1}$ Department of Materials Science and Engineering, University of Tennessee, Knoxville, TN 37996, USA \\ ${ }^{2}$ Materials Science and Technology Division, Oak Ridge National Laboratory, Oak Ridge, TN 37831, USA
}

\begin{abstract}
To understand the underlying strengthening mechanisms, thermal activation processes are investigated from stress-strain measurements with varying temperatures and strain rates for a family of equiatomic quinary, quaternary, ternary, and binary, face-center-cubic-structured, single phase solid-solution alloys, which are all subsystems of the FeNiCoCrMn high-entropy alloy. Our analysis suggests that the Labusch-type solution strengthening mechanism, rather than the lattice friction (or lattice resistance), governs the deformation behavior in equiatomic alloys. First, upon excluding the Hall-Petch effects, the activation volumes for these alloys are found to range from 10 to 1000 times the cubic power of Burgers vector, which are much larger than that required for kink pairs (i.e., the thermal activation process for the lattice resistance mechanism in body-center-cubic-structured metals). Second, the Labusch-type analysis for an N-element alloy is conducted by treating $\mathrm{M}$-elements $(\mathrm{M}<\mathrm{N})$ as an effective medium and summing the strengthening contributions from the rest of $\mathrm{N}-\mathrm{M}$ elements as individual solute species. For all equiatomic alloys investigated, a qualitative agreement exists between the measured strengthening effect and the Labusch strengthening factor from arbitrary $\mathrm{M}$ to $\mathrm{N}$ elements based on the lattice and modulus mismatches. Consequently, the Labusch strengthening factor provides a practical critique to understand and design such compositionally complex but structurally simple alloys.
\end{abstract}

Keywords: High entropy alloys; Equiatomic solid-solution alloys; Solution strengthening; Labusch model; Thermally activated processes

\footnotetext{
*Corresponding information: ygao7@utk.edu, beih@ornl.gov
} 


\section{Introduction}

A variety of multi-component solid-solution alloys have been found to form single-phase structures, as opposed to the formation of intermetallic compounds or multiple phases [1-3]. Yeh et al. [1] suggested that the configurational entropy of mixing, $\Delta S_{\text {conf }}=R \ln (N)$ with $R$ being the gas constant and $N$ being the number of alloying elements, may be large enough (e.g., $N \geq 5$ ) to overcome the enthalpies of intermetallic compounds, thus enabling the formation of single phase solid-solution alloy. Some recent studies have found that this concept is overly simplified in predicting the phase stability, but the terminology of high entropy alloy has been nevertheless adopted in this field [3-6]. Although the number of "real” equiatomic high entropy alloys with stable single-phase structures is limited, those that do exist, e.g., FeNiCoCrMn, often exhibit interesting mechanical properties, including high strength and ductility and unusual temperature dependence. Moreover, equiatomic alloys with 2 4 alloying elements can also be singe phase with FCC crystal structure, such as FeNiCoCr, FeNiCoMn, NiCoCrMn, FeNiCo, FeNiMn, NiCoCr, NiCoMn, FeNi and NiCo alloys, all of which are subsystems of the quinary FeNiCoCrMn high entropy alloy [7-11]. All these compositionally complex but structurally simple alloys, together with their parent high entropy alloy, display the similarly abnormal and exceptional temperature-dependent strength and ductility [12-14]. The strong temperature dependence of the yield strength is rather unusual in FCC metals but quintessential in BCC metals. Besides the above studies on mechanical behavior, multi-component solid-solution alloys, or high entropy alloys, or equiatomic or near-equiatomic alloys have also received extensive studies in their structural properties [15-17], elastic and thermal constants [18,19], irradiation resistance [20,21], and magnetic properties [22], among many others that have been extensively reviewed in [3].

Several deformation mechanisms have been proposed to understand the strength increase with respect to the temperature decrease in FCC-structured, equiatomic solid-solution alloys [1214]. Since the temperature dependence of the yield strength resembles the behavior of BCC metals, the lattice resistance, or lattice friction stress, to gliding dislocations is considered as a candidate mechanism [13,23,24]. The Peierls barrier depends on the dislocation core size; a narrow dislocation core leads to a high lattice resistance. In typical BCC metals, the resulting rate-determining mechanism is the thermally activated formation of kink pairs on a gliding screw dislocation, as shown in Fig. 1(a), which leads to a strong temperature dependence of the yield 
strength $[13,25]$. However, this model has some major drawbacks when adopted for equiatomic alloys. First, the transmission electron microscopy (TEM) studies did not observe local kinks, but rather saw the planar slip of dislocations in narrow bands [12]. Second, this model will find difficulties in resolving the different strengthening effects in various equiatomic alloys, since the dislocation cores have not been fully or qualitatively determined and they are probably sensitive to lattice distortions in Fig. 1(a). Third, while it is true that dislocation motions in FCC metals do not encounter the Peierls lattice resistance, many concentrated FCC alloys such as $\mathrm{Cu}-\mathrm{Al}$ and AlMg binary alloys exhibit significant increase of the yield stress with the reduction of temperature [26]. Thus the temperature dependence is not unique for BCC metals. Alternatively, the solution strengthening mechanism might play a critical role in these binary, ternary, quaternary, and quinary equiatomic alloys. Two commonly used models are schematically illustrated in Fig. 1(b). The Fleischer model considers the interaction of dislocations with strong pinning solute atoms on the gliding plane, giving rise to the square-root-power dependence of strengthening effect on the solute concentration [26-28]. The statistical theory developed by Labusch [29,30] models a gliding dislocation interacting with a forest of solute atoms in the space. Due to their lattice and modulus mismatches, the solute atoms acting as "stress centers" distort the straight dislocation line in competition to the excessive elastic energy resulting from local bending of the dislocation line. With the applied shear stress, the gliding non-straight dislocation line will constantly morph its shape and thus requires additional stress to move in the forest of "stress centers". As opposed to the Fleischer model that is applicable at extremely dilute concentrations, the Labusch model works in the entire concentration regime, and leads to the two-thirds-power dependence of the strengthening effect on the solute concentration. While keeping the same statistical framework, refinements of the Labusch model usually focus on a more rigorous description of solutedislocation interaction, such as by $a b$ initio calculations [31-33], or on the extension to multicomponent solid solution alloys [34-37].

To distinguish the above deformation mechanisms, we need to conduct the strength measurements with respect to temperature and strain rate, in order to characterize the thermal activation processes, and investigate a variety of equiatomic solid-solution alloys within the same set of constituent elements, in order to compare different degrees of lattice and modulus mismatches. Our experiments use a large set of FCC-structured equiatomic alloys, including the quinary FeNiCoCrMn, quaternary FeNiCoCr, FeNiCoMn, and NiCoCrMn, ternary FeNiCo, 
FeNiMn, NiCoCr, and NiCoMn, and binary FeNi and NiCo alloys, as well as FCC Ni and BCC Ta metals for comparisons. The flow stress can be represented by

$$
\sigma_{\text {flow }}\left(\varepsilon_{p}, T, \dot{\varepsilon}, d\right) \approx \sigma_{\text {flow }}^{\text {intrinsic }}\left(\varepsilon_{p}, T, \dot{\varepsilon}\right)+\sigma_{\text {flow }}^{\text {Hall-Petch }}\left(\varepsilon_{p}, d\right),
$$

and the yield stress, $\sigma_{Y}(T, \dot{\varepsilon}, d)=\left.\sigma_{\text {flow }}\right|_{\varepsilon_{p}=0.2 \%}$, by

$$
\sigma_{Y}(T, \dot{\varepsilon}, d) \approx \sigma_{Y}^{\text {intrinsic }}(T, \dot{\varepsilon})+\sigma_{Y}^{\text {Hall-Petch }}(d) \text {, }
$$

where $\varepsilon_{p}$ is the plastic strain, $d$ is the grain size, $\sigma_{Y}^{\text {Hall-Petch }}$ arises from grain boundary strengthening, and $\sigma_{Y}^{\text {intrinsic }}(T, \dot{\varepsilon})$ is the intrinsic strengths for the thermal activation analysis. Specifically, we note the following issues in relationship to the above equations.

- The Hall-Petch effects are often related to an athermal process that involves the pileup of dislocations at the grain boundaries. Previous tensile and Vicker's hardness tests $[12,13,38]$ for the quinary FeNiCoCrMn high-entropy alloy and some of its subsystems have confirmed that this term is insensitive to the test temperature up to $873 \mathrm{~K}$. Note the melting temperature is about 1,500 1,700 K. Single crystals of FeNiCoCr [14] are also available for complementary tests to validate Eq. (2).

- Our Fe-Ni-Co-Cr-Mn-based equiatomic alloys do not involve contributions from precipitate hardening and initial dislocation density, so the intrinsic strength, $\sigma_{Y}^{\text {intrinsic }}(T, \dot{\varepsilon})$, can be used to distinguish the lattice friction and Labusch-type models.

- Since Labusch model is based on a continuum elastic analysis of dislocations and solute atoms, its use in equiatomic alloys is dubious because of the poor definition of lattice and modulus mismatches. Therefore, it is more desirable to compare and contrast a wide range of equiatomic alloys, and to determine whether the synergistic variation of lattice and modulus mismatches leads to a qualitatively similar trend of variation of $\sigma_{Y}^{\text {intrinsic }}(T \rightarrow 0, \dot{\varepsilon})$. In other words, it is not recommended to conduct quantitative comparison between just two alloys whose strengths are close.

- The strain rate sensitivity and activation volumes, which can be extracted from $\sigma_{Y}^{\text {intrinsic }}(T, \dot{\varepsilon})$, will shed lights on the dominant rate-determining process, since the kink-pair mechanism involves an activation volume that is much smaller than that of the Labusch model. 
This paper is organized as follows. Materials and experimental methods will be presented in Section 2. Previous works have documented the yield strength variation within a temperature range of $77 \mathrm{~K} \sim 1,073 \mathrm{~K}$ but at a fixed strain rate of $10^{-3} \mathrm{~s}^{-1}[12,13]$. Tensile and strain-rate jump tests in this work will cover four orders of magnitude variation of strain rates, $10^{-5} \sim 10^{-1} \mathrm{~s}^{-1}$, at room temperature $(293 \mathrm{~K})$ and liquid nitrogen temperature $(77 \mathrm{~K})$. These test results will be analyzed in a thermal activation model in Section 3, and the calculated activation volumes will be compared to the proposed deformation mechanisms. Section 4 presents the Labusch-type analysis of this family of Fe-Ni-Co-Cr-Mn-based equiatomic alloys, in terms of the dependence of strengthening on various combinations of alloying elements. Conclusions will be presented in Section 5.

\section{Materials and Experimental Methods}

Of all the subsystems of the quinary FeNiCoCrMn high-entropy alloy, the single-phase and FCC-structured ones are listed in Table 1. Other combinations of the constituent elements do not form the equiatomic solid-solution alloys $[7,8]$. These alloys were produced by arc melting pure Fe, Ni, Co, Cr, and Mn (>99.9\% purity) in a water-cooled copper hearth under argon atmosphere. The arc-melted buttons were flipped and re-melted at least five times in order to ensure thorough mixing, followed by drop casting into copper molds to produce rectangular ingots with dimensions of $12.7 \mathrm{~mm} \times 25.4 \mathrm{~mm} \times 127 \mathrm{~mm}$. These ingots were homogenized for 24 hours at 1,473 K, water quenched, and cold rolled along the longitudinal ingot direction to a total thickness reduction of about 90 92\%.

Flat dog-bone-shaped specimens with a gauge length of $10 \mathrm{~mm}$ were cut from the coldrolled sheets by electrical discharge machining (EDM) with their longitudinal axes perpendicular to the rolling direction. Based on previous studies on the recrystallization and grain growth behavior of these alloys, the specimens were annealed at appropriate temperatures and times prescribed in [8], in order to obtain equiaxed microstructures with comparable grain sizes of $100 \sim 110 \mu \mathrm{m}$. All faces of their gauge sections were ground by 600-grit SiC paper. Nine Vickers microhardness indents spaced $1 \mathrm{~mm}$ apart were made along the specimen gauge lengths using a LECO LM 100 ${ }_{\mathrm{AT}}$ Vickers Hardness tester with a force of $200 \mathrm{~g}$. The elongation of the gauge length determined from the microhardness indents were used to calibrate the crosshead displacement of the tensile testing instrument and compute the plastic component of the strain. 
Quasi-static tensile tests were performed with an Instron screw-driven tensile testing machine with engineering strain rates ranging between $10^{-5}$ and $10^{-1} \mathrm{~s}^{-1}$ and temperatures of 77 and $293 \mathrm{~K}$. For $77 \mathrm{~K}$ tests, the specimens and grips were first fully immersed in a bath of liquid nitrogen for about 15 minutes before the test. During the tests, the baths were topped off as needed to keep the specimen and grips fully immersed during the tests. Room-temperature tests were performed in ordinary ambient air. Due to the long test durations, some of the low-strainrate tests were stopped at a plastic strain significantly before rupture. Strain-rate jump tests were conducted with the changes either from $10^{-5}$ and $10^{-3} \mathrm{~s}^{-1}$ or from $10^{-3}$ and $10^{-1} \mathrm{~s}^{-1}$. In each test, three jumps were made at engineering strain levels of about 5\%, 15\%, and $25 \%$.

\section{Analysis based on the Activation Volume Model}

Stress-strain curves of six representative equiatomic alloys are given in Fig. 2 with five strain rates and at two test temperatures. All these results exhibit significant strain hardening but a much smaller degree of strain rate hardening. The rupture strains, however, do not show a monotonic dependence on the strain rate, which will not be investigated in this work. The yield stress at the $0.2 \%$ plastic strain is plotted against the strain rate in Fig. 3 . Among these materials, $\mathrm{Ni}$ has a vanishing degree of strain rate sensitivity and its yield stresses at the two temperatures are almost identical. This is the behavior typically observed in single-element FCC metals. NiCoCr equiatomic alloys have the highest yield stress and correspondingly the highest degree of strain rate sensitivity.

\subsection{Removing the Hall-Petch effect}

Prior to the determination of the activation volume and strain rate sensitivity, the HallPetch effect must be excluded as discussed in Eq. (2). The relationship between the yield stress and the grain size has been measured for FiNiCoCr in [13]. As presented in Fig. 4(a), the HallPetch effect can be described by the inverse square root model,

$$
\sigma_{Y}(T, \dot{\varepsilon}, d) \approx \sigma_{Y}^{\text {intrinsic }}(T, \dot{\varepsilon})+k \frac{1}{\sqrt{d}} .
$$

Except for the data at $673 \mathrm{~K}$, all the other results have essentially the same slope, suggesting a weak temperature dependence of $k(T)$. The intercepts in Fig. 4(a) are the intrinsic yield stresses at the corresponding temperatures for the FeNiCoCr polycrystals. Tensile tests on FeNiCoCrMn [12] show similar behavior, and the Hall-Petch slope only decreases noticeably when the test 
temperature increases from $873 \mathrm{~K}$ to $1,073 \mathrm{~K}$. The above transitions agree qualitatively with the high temperature measurements in [39] when the test temperature exceeds about $0.4 T_{m}$ with $T_{m}$ being the melting temperature.

The validity of the linear superposition of intrinsic yield stress and Hall-Petch effect in Eq. (3) can be confirmed by the comparisons in Table 2. Note that all the equiatomic alloys in Table 1 deform by the classic $\{111\}\langle 1 \overline{1} 0\rangle$ slip systems. Therefore, the critical resolved shear stress (CRSS) is given by

$$
\tau_{\text {CRSS }}=\frac{\sigma_{Y}^{\text {intrinsic }}}{\text { Taylor Factor }},
$$

where the Taylor factor is 3.06. Results from our previous tests on FeNiCoCr single crystals [14] are also given in Table 2, from which the CRSS can be computed from the normal yield stress by

$$
\tau_{\text {CRSS }}=\frac{\left.\sigma_{Y}\right|_{\text {singlecrystal }}}{\text { Schmid Factor }},
$$

where the Schmid factor depends on the crystallographic orientation of the tensile specimens. Results from the above two methods give very close CRSS values, suggesting that the procedure to obtain $\sigma_{Y}^{\text {intrinsic }}(T, \dot{\varepsilon})$ from Eq. (3) and Fig. 4(a) be valid. It should be noted that the difference at $293 \mathrm{~K}$ appears to be large ( 31 MPa from polycrystal tests vs $\sim 41 \mathrm{MPa}$ by single crystal tests), because the Hall-Petch fitting for polycrystal results actually shows quite some scattering. The trend of decreasing CRSS with increasing temperature is the same for both tests.

\subsection{Activation volume}

The standard model for the thermally activated process is given by [40-42]

$$
\dot{\varepsilon}=\dot{\varepsilon}_{0} \exp \left(-\frac{\Delta G}{k_{B} T}\right)=\dot{\varepsilon}_{0} \exp \left(-\frac{\Delta F}{k_{B} T}+\frac{\sigma_{Y}^{\text {intrinsic }} \Delta V^{*}}{\sqrt{3} k_{B} T}\right),
$$

where $\Delta G$ is the activation energy, $\Delta F$ is the activation enthalpy, $k_{B}$ is the Boltzmann constant, and $\Delta V^{*}$ is the activation volume. The factor of $\sqrt{3}$ is introduced for the conversion between normal and shear strengths. The parameters, $\Delta F$ and $\Delta V^{*}$, can be fitted from the plot of $\sigma_{Y}^{\text {intrinsic }}$ versus $\ln \dot{\varepsilon}$ at different temperatures. Stress-strain curves from the strain-rate jump tests are given in Fig. 5. As expected, FCC Ni shows a vanishing degree of strain rate sensitivity, and 
BCC Ta shows a dramatic degree of strain rate sensitivity. Since the grain size does not change in each test, Eq. (6) can be converted to

$$
\Delta V^{*}=k_{B} T \frac{\sqrt{3} \ln \left(\dot{\varepsilon}_{2} / \dot{\varepsilon}_{1}\right)}{\Delta \sigma_{Y}}=k_{B} T \frac{\sqrt{3} \ln \left(\dot{\varepsilon}_{2} / \dot{\varepsilon}_{1}\right)}{\Delta \sigma_{Y}^{\text {intrinsic }}} .
$$

From the above equation, strain-rate jump test results in Fig. 5 can be used to determine the activation volume.

Before discussing the results in Table 3, we notice that the alloys which display a large degree of strain rate sensitivity also exhibit a rapid increase of strength with the decrease of temperature, as shown in Fig. 6(a). This is a general feature of thermally activated processes. Among the seven alloys in Table 3, NiCoCr, FeNiCoCr, and FeNiCoCrMn (ranked by their strengths) have the most significant dependence of strength on strain rate and temperature, so that their activation volumes are the lowest, i.e., $10 \sim 20 b^{3}$ at $77 \mathrm{~K}$ and $50 \sim 80 b^{3}$ at $293 \mathrm{~K}$. FeNiCo and FeNi have relatively weaker dependence on strain rate and temperature and thus have larger activation volumes, i.e., $\sim 30 b^{3}$ at $77 \mathrm{~K}$ and $60 \sim 100 b^{3}$ at $293 \mathrm{~K}$. NiCo and Ni have the weakest dependence and thus the highest activation volumes, i.e., $80 \sim 200 b^{3}$ at $77 \mathrm{~K}$ and $300 \sim 900 b^{3}$ at $293 \mathrm{~K}$. Experiments with variable strain rates and strain-rate jump tests lead to similar values of $\Delta V^{*}$, suggesting the validity of the activation volume model. Because only two temperatures were tested, the fitting result of $\Delta F$ varies significantly between $0.1 \sim 0.4 \mathrm{eV}$, and sometimes the fitting might be invalid.

The magnitude of the activation volumes in Table 3 can be used to differentiate various deformation mechanisms. It has been well established that the activation volume at room temperature for point defect migration is $0.02 \sim 0.1 b^{3}$, that for diffusional creep about $1 b^{3}$, that for kink pairs in gliding screw dislocation in BCC metals $1 \sim 5 b^{3}$, that for dislocation-twin interactions $1 \sim 100 b^{3}$, and that for forest dislocation cutting $\sim 1000 b^{3}$. NiCo and Ni both have very weak strain rate dependence, and the corresponding activation volume is as large as those due to the forest dislocation interactions. Even for the most rate-dependent and temperaturedependent equiatomic alloys, e.g., NiCoCr, FeNiCoCr, and FeNiCoCrMn, the corresponding activation volumes are still much larger than that needed for kink pairs. Referring back to Fig. 1(b), it is thus suggested that the dominant mechanism might not be the lattice resistance; it could be of the Labusch type, and the local bowing of the dislocation line involves an activation 
volume that is definitely larger than that needed in the kink-pair mechanism. More discussions along this line will be presented in Section 4 and Fig. 9.

The strain rate jump tests were conducted at about 5\%, 15\%, and 25\% strain levels, and the corresponding values of $\Delta V^{*}$ essentially have no difference from those obtained by the yield stress measurements. Previous work for FeNiCoCrMn in [12] found that the deformation mechanism shifts from dislocation mediated plasticity to nano-twinning with the decrease of temperature and the increase of plastic strain. Deformation twinning process continuously introduces new interfaces, and the interactions between dislocations and twin boundaries may result into additional strengthening - a phenomenon called dynamic Hall-Petch effect. Since no noticeable change of $\Delta V^{*}$ was found with the increase of strain levels and deformation twins were not found in all the equiatomic alloys investigated in this work, the correlation between twinning behavior and activation volume cannot be rigorously made in this work.

Finally, the strain-rate-sensitivity exponent, $m=\left.\frac{\partial \ln \sigma_{Y}^{\text {intrinsic }}}{\partial \ln \dot{\varepsilon}}\right|_{\varepsilon, T}$, is also fitted, e.g., in Fig. 4(b), and presented in Table 3. It exhibits the inverse trend when compared to the activation volume. That is, the stronger rate- and temperature-dependence the material has, the lower the activation volume and the higher the strain rate sensitivity exponent become.

\section{Labusch-Type Strengthening Analysis}

The Labusch model for solid solution strengthening has been briefly discussed in Fig. 1(b). Consider a solute species $i$, and define the modulus and lattice mismatches by

$$
\eta_{i}=\frac{1}{\mu} \frac{d \mu}{d x_{i}}, \delta_{i}=\frac{1}{a} \frac{d a}{d x_{i}}
$$

where $x_{i}$ is the molar fraction, $\mu$ and $\mu_{i}$ are the shear moduli, and $a$ and $a_{i}$ are the lattice constants of the alloy and the solute species, respectively. Following the formulation in [26,29,30,34-37], the additional strength is given by

$$
\Delta \sigma_{\text {solute-strengthening }}=f \mu\left[\left(\frac{\eta_{i}}{1+\frac{1}{2}\left|\eta_{i}\right|}\right)^{2}+\alpha^{2} \delta_{i}^{2}\right]^{2 / 3} x_{i}^{2 / 3}
$$

where $f$ is a dimensionless parameter, and $\alpha$ is a dimensionless parameter that describes the type of dislocations. For example, $3<\alpha<16$ for screw dislocations and $\alpha>16$ for edge 
dislocations [36]. When there is one solvent with multiple solute species $i, j, k, \ldots$, following the work of Toda-Caraballo and Rivera-Díaz-del-Castillo [36], we have

$$
\Delta \sigma_{\text {solute-strengthening }}=f \mu\left\{\left[\left(\frac{\eta_{i}}{1+\frac{1}{2}\left|\eta_{i}\right|}\right)^{2}+\alpha^{2} \delta_{i}^{2}\right] x_{i}+\left[\left(\frac{\eta_{j}}{1+\frac{1}{2}\left|\eta_{j}\right|}\right)^{2}+\alpha^{2} \delta_{j}^{2}\right] x_{j}+\ldots\right\}^{2 / 3} \text {. }
$$

When using the above equations to analyze the equiatomic alloys, we employ the following practical treatments. First, in equiatomic alloys, to distinguish solvent and solute atoms, we can group arbitrary M-elements out of the total of N-elements as the "effective solvent”. Thus we define a Labusch-strengthening factor as

$$
L_{M \rightarrow N}=\mu_{N}\left\{\sum_{i=M+1}^{N}\left[\left(\frac{\eta_{i}}{1+\frac{1}{2}\left|\eta_{i}\right|}\right)^{2}+\alpha^{2} \delta_{i}^{2}\right] x_{i}\right\}^{2 / 3}
$$

where $\mu_{N}$ is the shear modulus of the N-element alloy. For example, the above factor can be used to investigate the strengthening effect of Co from FeNi to FeNiCo, or that of Co and Cr from $\mathrm{Ni}$ to $\mathrm{NiCoCr}$, or other combinations.

Second, the Labusch-type strengthening model in Eqs. (9)-(11) only considers athermal effects. The plots of $\sigma_{Y} \sim T$ in Fig. 6(a) must be extrapolated to absolute zero temperature, and the grain-size effect must be excluded as shown in Fig. 6(b). Hall-Petch slopes are only available for tensile tests of FeNiCoCrMn and FeNiCoCr, but Vicker's hardness tests were performed for all other alloys without $\mathrm{Mn}$ in [8] and the related slopes, $k_{H V}$, are given in Table 1 . The Vicker's hardness, as other hardness measurements based on sharp indenters, is proportional to the flow stress at the indentation strain that depends on the apex angle of the indenter [43]. Thus the HallPetch effect determined from the yield stress (i.e., flow stress at $0.2 \%$ plastic strain) and that from the Vicker's hardness (i.e., flow stress at the indentation strain of about 0.07) are not necessarily proportional to each other. Nevertheless, a revisit to the tests results in [8] suggests that all equiatomic alloys without Mn have similar Hall-Petch effects, the Hall-Petch effects of equiatomic alloys with $\mathrm{Mn}$ are reduced to about half, and Ni polycrystals have almost vanishing Hall-Petch effects when compared to all the other alloys.

Third, mismatches in Eq. (8) require the knowledge of lattice constants and moduli of elemental species, e.g., lattice mismatch of $\mathrm{Cr}$ in FeNiCoCr by $\delta_{C r}=\frac{a_{C r}-a_{F e N i C o C r}}{\left(1-x_{C r}\right) a_{F e N i C o C r}}$. Fe, Co, 
$\mathrm{Cr}$, and $\mathrm{Mn}$ are not FCC-structured at room and low temperatures, so their related parameters are not known [44]. Assuming the Vegard law for the lattice parameters, the following relationships are derived for all the alloys except those with Mn in Fig. 6:

$$
\begin{gathered}
\left(a_{N i}+a_{F e}\right) / 2=a_{F e N i}, \\
\left(a_{N i}+a_{C o}\right) / 2=a_{N i C o}, \\
\left(a_{N i}+a_{C o}+a_{C r}\right) / 3=a_{N i C o C r}, \\
\left(a_{N i}+a_{F e}+a_{C o}\right) / 3=a_{N i F e C o}, \\
\left(a_{N i}+a_{F e}+a_{C o}+a_{C r}\right) / 4=a_{F e N i C o C r} .
\end{gathered}
$$

The above five equations involve three unknowns, $a_{F e}, a_{C r o}$ and $a_{C r}$, which is an overdetermined system. The least $\mathrm{L}^{2}$-norm solution is calculated using the pseudo-inverse method [45]. For similar operations on the elastic constants, it should be noted that the Fe-Ni system does not permit a linear relationship of the elastic constants, due to the invar effect [44]. Therefore, the equation of $\left(\mu_{\mathrm{Ni}}+\mu_{\mathrm{Fe}}\right) / 2=\mu_{\mathrm{FeNi}}$ should be discarded. Final results are given in Table 4. It should also be noted that all these alloys have very similar thermal expansion coefficients and temperature dependence of the elastic constants. Available data in $[18,19]$ have been incorporated in the above calculations, but they have little effects in our mismatch calculations.

Several examples of the Labusch strengthening factor in Eq. (11) are given in Fig. 7. From $\mathrm{Ni}$ to $\mathrm{NiCo}$, the dependence on $\alpha$ is very weak because $\mathrm{Ni}$ and Co have very similar lattice constants. $\mathrm{Cr}$ has the highest modulus mismatch with other elements, so curves like $\mathrm{NiCo} \rightarrow \mathrm{NiCoCr}$ and $\mathrm{Ni} \rightarrow \mathrm{FeNiCoCr}$ are higher than the other curves. The athermal strengthening of the intrinsic yield stress is summarized in Fig. 8(a), and the corresponding Labusch factors with $\alpha=16$, normalized by $\mu_{N i}$, are presented in Fig. 8(b). The overall trends of $\left.\Delta \sigma_{Y}^{\text {intrinsic }}\right|_{T \rightarrow 0}$ and $L_{M \rightarrow N} / \mu_{N i}$ have a qualitative agreement, suggesting the validity of the Labusch-type strengthening analysis for equiatomic alloys. Again we note that among all the alloying elements, $\mathrm{Cr}$ has the highest modulus mismatch, and thus enhances the yield strength noticeably, as shown by the example of NiCo $\rightarrow$ NiCoCr. A large deviation is found for FeNi likely due to the invar effect. Predictions based on $(N-1) \rightarrow N$ are usually less reliable than those based on 
$1 \rightarrow N$, as shown by the examples of $\mathrm{NiCo} \rightarrow \mathrm{NiCoCr}$ and $\mathrm{Ni} \rightarrow \mathrm{NiCoCr}$. Note that Labusch model does not take into considerations the stacking fault energy, long-range and/or short-range order, and valency mismatch. Also considering the continuum elastic model of solute atoms, the general agreement in Fig. 8 suggests Labusch model at least captures the dominant contributions.

In the Labusch model, plastic deformation is realized by the motion of non-straight dislocations and by a thermally activated process that involves the local bowing of dislocation lines, as illustrated in Fig. 9(a). The thermal activation model in Eq. (6) essentially takes a Taylor expansion of the activation energy. Alternatively, for the solution strengthening, Caillard and Martin [40] present the general form,

$$
\Delta G=\Delta F\left[1-\left(\frac{\sigma_{Y}^{\text {intrinsic }}(T, \dot{\varepsilon})}{\sigma_{\text {athermal }}}\right)^{p}\right]^{q},
$$

so that,

$$
\frac{\sigma_{Y}^{\text {intrinsic }}(T, \dot{\varepsilon})}{\sigma_{\text {athermal }}}=\left[1-\left(\frac{k_{B} T}{\Delta F} \ln \frac{\dot{\varepsilon}_{0}}{\dot{\varepsilon}}\right)^{1 / q}\right]^{1 / p} .
$$

The choices of $p$ and $q$ depend on the detailed process of the dislocation-solute interaction. Labusch and Haasen [26] suggested $p=2 / 3$ and $q=3 / 2$, while Leyson and Curtin [32] used $p=1$ and $q=3 / 2$. Fitting to the intrinsic strength data for FeNiCoCr in Fig. 6(b) gives $p=0.2, q=1.2$, and $\frac{k_{B}}{\Delta F} \ln \frac{\dot{\varepsilon}_{0}}{\dot{\varepsilon}} \approx 6.48 \times 10^{-4} \mathrm{~K}^{-1}$. Although it is not advisable to make a quantitative comparison, we do find an increase of the deviation of these parameters $p$ and $q$ from those predicted by the solution strengthening models in [26,32], as we move from the bottom to the top alloys in Fig. 6(a). This accompanies with the decrease of the activation volume and the increase of element number (except for $\mathrm{NiCoCr}$ ).

The above findings suggest a thermal activation process schematically shown in Fig. 9. Multiple elements in the equiatomic alloy introduce short-range, medium-range, and long-range stress fields. For those with large $\Delta V^{*}$, the corresponding thermally activated process involves a long-range bowing of the dislocation line in Fig. 9(a). For those alloys with small $\Delta V^{*}$, shortrange effects have more noticeable contributions. It is well known that solute atoms may reduce stacking fault energy [10] or lead to short-range ordering that promotes planar slip, i.e., localization of dislocations into a narrow band [12]. The short-range lattice distortion in Fig. 1(a) 
may lead to local fluctuations on the long-range bowing, as given in Fig. 9(b), so that the mere consideration of the Labusch model becomes inaccurate for small $\Delta V^{*}$. A rigorous analysis of interactions between short-range distortions and long-range Labusch analysis is not clear yet, but likely requires the core structure study and mobility simulations. A more refined model based on atomistic scenario is awaited, despite the great challenges such as $a b$ initio calculations with multiple elements.

\section{Conclusions}

Multi-component equiatomic alloys display exceptional mechanical properties such as high strength and ductility at low temperatures. To clarify the thermal activation mechanisms, stress-strain measurements at two temperatures and with four strain rates, together with strainrate jump tests, were performed in this study for a family of equiatomic solid-solution alloys which are subsystems of the FeNiCoCrMn high-entropy alloy. These materials were melted, drop-cast, homogenized, cold-rolled, and recrystallized to produce equiaxed microstructures with comparable grain sizes. The exclusion of athermal Hall-Petch effects is confirmed by the comparisons between $\mathrm{FeNiCoCr}$ polycrystals and single crystals. The activation volume is found to be $>300 b^{3}$ for $\mathrm{Ni}$ and NiCo which show negligible temperature dependence, suggesting the validity of the classic forest dislocation hardening mechanism. Even for equiatomic alloys with a high degree of temperature dependence, the activation volumes are about $50 \sim 80 b^{3}$ at $293 \mathrm{~K}$ and much larger than those associated with the lattice friction model. Moreover, the Labusch strengthening factor in Eq. (11), based on lattice and modulus mismatches, leads to qualitatively the same trends of athermal strengthening effects as in the experiments. The thermal activated process is believed to be dominated by long-range bowing of non-straight dislocations, while short-range effects contribute to this process but only for alloys with very low activation volumes.

\section{Acknowledgements}

This research was supported by the U.S. Department of Energy, Office of Science, Basic Energy Sciences, Materials Sciences and Engineering Division. 


\section{References}

[1] J.W. Yeh, S.K. Chen, S.J. Lin, J.Y. Gan, T.S. Chin, T.T. Shun, C.H. Tsau, S.Y. Chang, Nanostructured high-entropy alloys with multiple principal elements: novel alloy design concepts and outcomes, Adv. Eng. Mater. 6 (2004) 299-303.

[2] B. Cantor, I.T.H. Chang, P. Knight, A.J.B. Vincent, Microstructural development in equiatomic multicomponent alloys, Mater. Sci. Eng. A 375-377 (2004) 213-218.

[3] Y. Zhang, T.T. Zuo, Z. Tang, M.C. Gao, K.A. Dahmen, P.K. Liaw, Z.P. Lu, Microstructures and properties of high-entropy alloys, Prog. Mater. Sci. 61 (2014) 1-93.

[4] S. Guo, Q. Hu, C. Ng, C.T. Liu, More than entropy in high-entropy alloys: forming solid solutions or amorphous phase, Intermetallics 41 (2013) 96-103.

[5] F. Otto, Y. Yang, H. Bei, E.P. George, Relative effects of enthalpy and entropy on the phase stability of equiatomic high-entropy alloys, Acta Mater. 61 (2013) 2628-.

[6] M.C. Troparevsky, J.R. Morris, P.R.C. Kent, A.R. Lupini, G.M. Stocks, Criteria for predicting the formation of single-phase high-entropy alloys, Phys. Rev. X 5 (2015) 011041.

[7] Bei H. US Patent 2013/0108502 A1.

[8] Z. Wu, H. Bei, F. Otto, G.M. Pharr, E.P. George, Recovery, recrystallization, grain growth and phase stability of a family of FCC-structured multi-component equiatomic solid solution alloys, Intermetallics 46 (2014) 131-140.

[9] Z. Wu, H. Bei, Microstructures and mechanical properties of compositionally complex Co-free FeNiMnCr 18 FCC solid solution alloy, Mater. Sci. Eng. A 640 (2015) 217-224.

[10] Z. Wu, C.M. Parish, H. Bei, Nano-twin mediated plasticity in carbon-containing FeNiCoCrMn high entropy alloys, J. Alloys Comp. 647 (2015) 815-822.

[11] Wu Z. PhD Thesis, University of Tennessee, Knoxville TN, USA, 2014.

[12] F. Otto, A. Dlouhý, Ch. Somsen, H. Bei, G. Eggeler, E.P. George, The influences of temperature and microstructure on the tensile properties of a CoCrFeMnNi high-entropy alloy, Acta Mater. 61 (2013) 5743-5755.

[13] Z. Wu, H. Bei, G.M. Pharr, E.P. George, Temperature dependence of the mechanical properties of equiatomic solid solution alloys with face-centered cubic crystal structures, Acta Mater. 81 (2014) 428-441.

[14] Z. Wu, Y.F. Gao, H. Bei, Single crystal plastic behavior of a single-phase, face-centercubic-structured, equiatomic FeNiCrCo alloy, Scripta Mater. 109 (2015) 108-112.

[15] Y.J. Zhou, Y. Zhang, F.J. Wang, G.L. Chen, Phase transformation induced by lattice distortion in multiprincipal component $\mathrm{CoCrFeNiCu}_{\mathrm{x}} \mathrm{Al}_{1-\mathrm{x}}$ solid-solution alloys, Appl. Phys. Lett. 92 (2008) 241917.

[16] Y. Zhang, Y.J. Zhou, J.P. Lin, G.L. Chen, P.K. Liaw, Solid-solution phase formation rules for multi-component alloys, Adv. Eng. Mater. 10 (2008) 534-538.

[17] Y. Zou, S. Maiti, W. Steurer, R. Spolenak, Size-dependent plasticity in an $\mathrm{Nb}_{25} \mathrm{Mo}_{25} \mathrm{Ta}_{25} \mathrm{~W}_{25}$ refractory high-entropy alloys, Acta Mater. 65 (2014) 85-97.

[18] A. Haglund, M. Koehler, D. Catoor, E.P. George, V. Keppens, Polycrystalline elastic moduli of a high-entropy alloy at cryogenic temperatures, Intermetallics 58 (2015) 62-64.

[19] G. Laplanche, P. Gadaud, O. Horst, F. Otto, G. Eggeler, E.P. George, Temperature dependences of the elastic moduli and thermal expansion coefficient of an equiatomic, single-phase CoCrFeMnNi high-entropy alloy, J. Alloys Comp. 623 (2015) 348-353.

[20] Y. Zhang, G.M. Stocks, K. Jin, C. Lu, H. Bei, B.C. Sales, L. Wang, L.K. Béland, R.E. Stoller, G.D. Samolyuk, M. Caro, A. Caro, W.J. Weber, Influence of chemical disorder 
on energy dissipation and defect evolution in concentrated solid solution alloys, Nature Comm. 6 (2015) 8736.

[21] K. Jin, C. Lu, L.M. Wang, J. Qu, W.J. Weber, Y. Zhang, H. Bei, Effects of compositional complexity on the ion-irradiation induced swelling and hardening in Ni-containing equiatomic alloys, Scripta Mater. 119 (2016) 65-70.

[22] B.C. Sales, K. Jin, H. Bei, G.M. Stocks, G.D. Samolyuk, A.F. May, M.A. McGuire, Quantum critical behavior in a concentrated ternary solid solution, Sci. Rep. 6 (2016) 26179.

[23] R.S. Mishra, N. Kumar, M. Komarasamy, Lattice strain framework for plastic deformation in complex concentrated alloys including high entropy alloys, Mater. Sci. Tech. 31 (2015) 1259-1263.

[24] M. Komarasamy, N. Kumar, R.S. Mishra, P.K. Liaw PK, Anomalies in the deformation mechanism and kinetics of coarse-grained high entropy alloy, Mater. Sci. Eng. A 654 (2016) 256-263.

[25] H. Lim, C.C. Battaile, J.D. Carroll, B.L. Boyce, C.R. Weinberger, A physically based model of temperature and strain rate dependent yield in BCC metals: implementation into crystal plasticity, J. Mech. Phys. Solids 74 (2015) 80-96.

[26] Haasen P. Physical Metallurgy. Third Edition, Cambridge University Press, UK (1996).

[27] R.L. Fleischer, Solution hardening, Acta Metall. 9 (1961) 996-1000.

[28] R.L. Fleischer, Substitutional solution hardening, Acta Metall. 11 (1963) 203-209.

[29] R. Labusch, A statistical theory of solid solution hardening, Phys. Stat. Sol. 41 (1970) 659-669.

[30] R. Labusch, Statistische theorien der mischkristallhärtung, Acta Metall. 20 (1972) 917927.

[31] G.P.M. Leyson, W.A. Curtin, L.G. Hector Jr, C.F. Woodward, Quantitative prediction of solute strengthening in aluminum alloys, Nature Mater. 9 (2010) 750-755.

[32] G.P.M. Leyson, W.A. Curtin, Friedel vs. Labusch: the strong/weak pinning transition in solute strengthened metals, Phil. Mag. 93 (2013) 2428-2444.

[33] D. Ma, M. Friák, J. von Pezold, D. Raabe, J. Neugebauer, Computationally efficient and quantitatively accurate multiscale simulation of solid-solution strengthening by ab initio calculation, Acta Mater. 85 (2015) 53-6.

[34] L.A. Gypen, A. Deruyttere, Multi-component solid solution hardening, J. Mater. Sci. 12 (1977) 1028-1033.

[35] C. Pöhl, J. Schatte, H. Leitner, Solid solution hardening of molybdenum-hafnium alloys: experiments and modeling, Mater. Sci. Eng. A 559 (2013) 643-650.

[36] I. Toda-Caraballo, P.E.J. Rivera-Díaz-del-Castillo, Modelling solid solution hardening in high entropy alloys, Acta Mater. 85 (2015) 14-23.

[37] I. Toda-Caraballo, J.S. Wróbel, S.L. Dudarev, D. Nguyen-Manh, P.E.J. Rivera-Díaz-delCastillo, Interatomic spacing distribution in multicomponent alloys, Acta Mater. 97 (2015) 156-169.

[38] W.H. Liu, Y. Wu, J.Y. He, T.G. Nieh, Z.P. Lu, Grain growth and the Hall-Petch relationship in a high-entropy FeCrNiCoMn alloy, Scripta Mater. 68 (2013) 526-529.

[39] J.Y. He, C. Zhu, D.Q. Zhou, W.H. Liu, T.G. Nieh, Z.P. Lu, Steady state flow of the FeCoNiCrMn high entropy alloy at elevated temperatures, Intermetallics 55 (2014) 9-14.

[40] Caillard D, Martin JL. Thermally Activated Mechanisms in Crystal Plasticity. Pergamon Press (2003). 
[41] Y.M. Wang, A.V. Hamza, E. Ma, Temperature-dependent strain rate sensitivity and activation volume of nanocrystalline Ni, Acta Mater. 54 (2006) 2715-2726.

[42] H. Li, H. Choo, P.K. Liaw, The effect of temperature on strain rate sensitivity in a nanocrystalline Ni-Fe alloy, J. Appl. Phys. 101 (2007) 063536.

[43] G.M. Pharr, E.G. Herbert, Y.F. Gao, The indentation size effect: a critical examination of experimental observations and mechanistic interpretations, Annu. Rev. Mater. Res. 40 (2010) 271-292.

[44] H.M. Ledbetter, R.P. Reed, Elastic properties of metals and alloys, 1. iron, nickel, and iron-nickel alloys, J. Phys. Chem. Ref. Data 2 (1973) 531-617.

[45] Y.F. Gao, B.C. Larson, J.H. Lee, L. Nicola, J.Z. Tischler, G.M. Pharr, Lattice rotation patterns and strain gradient effects in face-center-cubic single crystals under spherical indentation, J. Appl. Mech. 82 (2015) 061007. 


\section{Table Captions}

Table 1 The melting temperature, elastic constants, lattice parameters, grain sizes, and Hall-Petch coefficients of the equiatomic alloys investigated in this study. Data are compiled from [8,11-13]. Rate-dependence tests at $293 \mathrm{~K}$ and $77 \mathrm{~K}$ were conducted in this work.

Table 2 Critical resolved shear stress (CRSS) values for FeNiCoCr alloy. For polycrystals, CRSS is obtained from the ratio of intrinsic yield stress (at $10^{-3} \mathrm{~s}^{-1}$ strain rate, and excluding the Hall-Petch effect) [13] and the Taylor factor. For single crystals, CRSS is obtained from the ratio of tensile yield stress and the Schmid factor [14].

Table 3 The activation volume, $\Delta V^{*}$, the activation enthalpy, $\Delta F$, and the strain-ratesensitivity exponent, $m$, for FeNiCoCr equiatomic alloys obtained from the strain rate sensitivity results in Fig. 3 and strain-rate jump test results in Fig. 5. $\Delta V^{*}$ can be normalized by $b^{3}$ where $b$ is the Burgers vector.

Table 4 Assuming a linear relationship between the lattice constants and shear moduli of equiatomic alloys and their constituent elements (except the FeNi alloy), the pseudo-inverse analysis leads to the model parameters for $\mathrm{Fe}, \mathrm{Co}, \mathrm{Cr}$, and $\mathrm{Mn}$. Refer to Eq. (12). 
Table 1 The melting temperature, elastic constants, lattice parameters, grain sizes, and Hall-Petch coefficients of the equiatomic alloys investigated in this study. Data are compiled from [8,11-13]. Rate-dependence tests at $293 \mathrm{~K}$ and $77 \mathrm{~K}$ were conducted in this work.

\begin{tabular}{|c|c|c|c|c|c|c|c|c|c|}
\hline \multicolumn{2}{|c|}{ Equiatomic alloys } & $\begin{array}{c}\mathrm{T}_{\mathrm{m}}(\mathrm{K}) \\
{[13]}\end{array}$ & $\begin{array}{c}\text { Shear } \\
\text { modulus, } \\
\mu(\mathrm{GPa}) \\
{[13]}\end{array}$ & $\begin{array}{c}\text { Poisson's } \\
\text { ratio, } v \\
\text { [13] }\end{array}$ & $\begin{array}{l}\text { FCC lattice } \\
\text { parameter, } \\
a(\AA \hat{)})[11]\end{array}$ & $\begin{array}{c}\text { Grain size } \\
\text { used in } \\
\text { strength T } \\
\text { tests }(\mu \mathrm{m}) \\
{[12,13]}\end{array}$ & $\begin{array}{l}\text { Grain size } \\
\text { used in rate- } \\
\text { sensitivity } \\
\text { tests }(\mu \mathrm{m})\end{array}$ & $\begin{array}{c}\text { Hall-Petch } \\
\text { slope, } \mathrm{k} \\
\left(\mathrm{MPa} \cdot \mu \mathrm{m}^{1 / 2}\right) \\
\text { at } 293 \mathrm{~K} \\
{[8,12]}\end{array}$ & $\begin{array}{c}\text { Hall-Petch } \\
\text { slope, } \mathrm{k}_{\mathrm{HV}} \\
\left(\mathrm{HV} \cdot \mu \mathrm{m}^{1 / 2}\right) \text { at } \\
293 \mathrm{~K}[8]\end{array}$ \\
\hline Quinary & FeNiCoCrMn & 1,553 & 80 & 0.26 & 3.5991 & 50 & $100 \sim 110$ & 494.0 & - \\
\hline \multirow[t]{3}{*}{ Quaternary } & FeNiCoCr & 1,695 & 82 & 0.28 & 3.5715 & 24 & $100 \sim 110$ & 854.8 & 165.5 \\
\hline & FeNiCoMn & 1,533 & 77 & 0.22 & 3.5919 & 48 & -- & -- & -- \\
\hline & NiCoCrMn & 1,489 & 78 & 0.25 & 3.5892 & 36 & -- & -- & -- \\
\hline \multicolumn{10}{|c|}{ Equiatomic mixtures of FeNiCrMn and FeCoCrMn do not form single phase alloys } \\
\hline \multirow[t]{4}{*}{ Ternary } & FeNiCo & 1,724 & 60 & 0.35 & 3.5690 & 28 & $100 \sim 110$ & -- & 131.1 \\
\hline & FeNiMn & 1,473 & 73 & 0.24 & 3.6160 & 30 & -- & -- & -- \\
\hline & $\mathrm{NiCoCr}$ & 1,690 & 87 & 0.30 & 3.5590 & 41 & $100 \sim 110$ & -- & 197.3 \\
\hline & NiCoMn & 1,462 & 77 & 0.23 & 3.5977 & 32 & -- & -- & -- \\
\hline \multicolumn{10}{|c|}{ Equiatomic mixtures of FeNiCr, FeCoCr, FeCoMn, FeCrMn, NiCrMn, CoCrMn do not form single phase alloys } \\
\hline \multirow[t]{3}{*}{ Binary } & $\mathrm{FeNi}$ & 1,703 & 61 & 0.34 & 3.5826 & 35 & $100 \sim 110$ & -- & 113.4 \\
\hline & NiCo & 1,735 & 84 & 0.29 & 3.5345 & 35 & $100 \sim 110$ & -- & 167.1 \\
\hline & \multicolumn{8}{|c|}{ Equiatomic mixtures of FeCo, FeCr, FeMn, NiCr, NiMn, CoCr, CoMn, CrMn do not form single phase alloys } & \\
\hline \multirow[t]{2}{*}{ Elemental } & $\mathrm{Ni}$ & 1,728 & 76 & 0.31 & 3.5238 & 85 & $100 \sim 110$ & -- & 34.3 \\
\hline & \multicolumn{8}{|c|}{$\mathrm{Fe}, \mathrm{Co}, \mathrm{Cr}, \mathrm{Mn}$ do not have FCC structure at room temperature } & \\
\hline
\end{tabular}


Table 2 Critical resolved shear stress (CRSS) values for FeNiCoCr alloy. For polycrystals, CRSS is obtained from the ratio of intrinsic yield stress (at $10^{-3} \mathrm{~s}^{-1}$ strain rate, and excluding the Hall-Petch effect) [13] and the Taylor factor. For single crystals, CRSS is obtained from the ratio of tensile yield stress and the Schmid factor [14].

\begin{tabular}{ccccc}
\hline & \multicolumn{2}{c}{ FeNiCoCr polycrystals } & \multicolumn{2}{c}{ FeNiCoCr single crystals } \\
\hline Temperature & $\begin{array}{c}\text { Intrinsic yield } \\
\text { stress (MPa) }\end{array}$ & $\begin{array}{c}\text { CRSS } \\
(\mathrm{MPa})\end{array}$ & $\begin{array}{c}\text { Yield stress } \\
(\mathrm{MPa})\end{array}$ & $\begin{array}{c}\text { CRSS } \\
(\mathrm{MPa})\end{array}$ \\
\hline $77 \mathrm{~K}$ & 290.2 & 94.8 & $\begin{array}{c}\text { Depends on } \\
\text { orientation }\end{array}$ & $95.5 \pm 2.5$ \\
$203 \mathrm{~K}$ & 149.8 & 49.0 & $\begin{array}{c}-- \\
\text { Depends on }\end{array}$ & -- \\
$293 \mathrm{~K}$ & 94.2 & 30.8 & orientation & $41.3 \pm 1.7$ \\
$473 \mathrm{~K}$ & 58.1 & 19.0 & -- & -- \\
$673 \mathrm{~K}$ & 55.8 & 18.2 & -- & -- \\
\hline
\end{tabular}

Table 3 The activation volume, $\Delta V^{*}$, the activation enthalpy, $\Delta F$, and the strain-ratesensitivity exponent, $m$, for FeNiCoCr equiatomic alloys obtained from the strain rate sensitivity results in Fig. 3 and strain-rate jump test results in Fig. 5. $\Delta V^{*}$ can be normalized by $b^{3}$ where $b$ is the Burgers vector.

\begin{tabular}{|c|c|c|c|c|c|c|c|}
\hline Polycrystals & Temperature & \multicolumn{4}{|c|}{ Tests with variable strain rates } & \multicolumn{2}{|c|}{ Strain rate jump tests } \\
\hline & & $\Delta F(\mathrm{eV})$ & $\Delta V^{*}\left(\mathrm{~nm}^{3}\right)$ & $\Delta V^{*}$ & $m$ & $\Delta V^{*}\left(\mathrm{~nm}^{3}\right)$ & $\Delta V^{*}$ \\
\hline FeNiCoCrMn & $\begin{array}{c}77 \mathrm{~K} \\
293 \mathrm{~K}\end{array}$ & -- & $\begin{array}{l}0.120 \\
1.267\end{array}$ & $\begin{array}{l}7.25 b^{3} \\
76.8 b^{3}\end{array}$ & $\begin{array}{l}0.0359 \\
0.0260\end{array}$ & $\begin{array}{l}0.303 \\
1.344\end{array}$ & $\begin{array}{l}18.4 b^{3} \\
81.5 b^{3}\end{array}$ \\
\hline FeNiCoCr & $\begin{array}{c}77 \mathrm{~K} \\
293 \mathrm{~K}\end{array}$ & 0.141 & $\begin{array}{l}0.185 \\
0.991\end{array}$ & $\begin{array}{l}11.5 b^{3} \\
61.6 b^{3}\end{array}$ & $\begin{array}{l}0.0263 \\
0.0480\end{array}$ & $\begin{array}{l}0.306 \\
1.241\end{array}$ & $\begin{array}{l}19.0 b^{3} \\
77.0 b^{3}\end{array}$ \\
\hline FeNiCo & $\begin{array}{c}77 \mathrm{~K} \\
293 \mathrm{~K}\end{array}$ & 0.408 & $\begin{array}{l}0.446 \\
0.993\end{array}$ & $\begin{array}{l}27.7 b^{3} \\
61.8 b^{3}\end{array}$ & $\begin{array}{l}0.0169 \\
0.0547\end{array}$ & $\begin{array}{l}0.453 \\
1.792\end{array}$ & $\begin{array}{l}28.2 b^{3} \\
77.2 b^{3}\end{array}$ \\
\hline $\mathrm{NiCoCr}$ & $\begin{array}{c}77 \mathrm{~K} \\
293 \mathrm{~K}\end{array}$ & 0.299 & $\begin{array}{l}0.215 \\
0.743\end{array}$ & $\begin{array}{l}13.5 b^{3} \\
46.6 b^{3}\end{array}$ & $\begin{array}{l}0.0150 \\
0.0396\end{array}$ & $\begin{array}{l}0.244 \\
0.806\end{array}$ & $\begin{array}{l}15.3 b^{3} \\
50.6 b^{3}\end{array}$ \\
\hline FeNi & $\begin{array}{c}77 \mathrm{~K} \\
293 \mathrm{~K}\end{array}$ & 0.404 & $\begin{array}{l}0.470 \\
1.397\end{array}$ & $\begin{array}{l}28.9 b^{3} \\
85.9 b^{3}\end{array}$ & $\begin{array}{l}0.0091 \\
0.0386\end{array}$ & $\begin{array}{l}0.530 \\
1.698\end{array}$ & $\begin{array}{c}32.6 b^{3} \\
104.4 b^{3}\end{array}$ \\
\hline NiCo & $\begin{array}{c}77 \mathrm{~K} \\
293 \mathrm{~K}\end{array}$ & -- & $\begin{array}{l}1.137 \\
6.224\end{array}$ & $\begin{array}{c}72.8 b^{3} \\
398.7 b^{3}\end{array}$ & $\begin{array}{l}0.0220 \\
0.0195\end{array}$ & $\begin{array}{l}1.338 \\
4.607\end{array}$ & $\begin{array}{c}85.7 b^{3} \\
295.1 b^{3}\end{array}$ \\
\hline $\mathrm{Ni}$ & $\begin{array}{c}77 \mathrm{~K} \\
293 \mathrm{~K}\end{array}$ & -- & $\begin{array}{l}2.930 \\
13.44\end{array}$ & $\begin{array}{l}189.4 b^{3} \\
868.7 b^{3}\end{array}$ & $\begin{array}{l}0.0100 \\
0.0088\end{array}$ & $\begin{array}{l}1.816 \\
12.08\end{array}$ & $\begin{array}{l}117.4 b^{3} \\
780.8 b^{3}\end{array}$ \\
\hline
\end{tabular}


Table $4 \quad$ Assuming a linear relationship between the lattice constants and shear moduli of equiatomic alloys and their constituent elements (except the FeNi alloy), the pseudo-inverse analysis leads to the model parameters for $\mathrm{Fe}, \mathrm{Co}, \mathrm{Cr}$, and $\mathrm{Mn}$. Refer to Eq. (12).

\begin{tabular}{|c|c|c|c|c|c|c|c|c|}
\hline $\begin{array}{l}\text { Pseudo- } \\
\text { inverse } \\
\text { analysis }\end{array}$ & $a_{\mathrm{Fe}}(\AA \hat{)})$ & $\begin{array}{c}\mu_{\mathrm{Fe}} \\
(\mathrm{GPa})\end{array}$ & $a_{\mathrm{Co}}(\AA \grave{)})$ & $\begin{array}{c}\mu_{\mathrm{Co}} \\
(\mathrm{GPa})\end{array}$ & 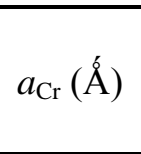 & $\begin{array}{c}\mu_{\mathrm{Cr}} \\
(\mathrm{GPa})\end{array}$ & 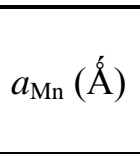 & $\begin{array}{c}\mu_{\mathrm{Mn}} \\
(\mathrm{GPa})\end{array}$ \\
\hline $\begin{array}{l}\text { Fe-Ni-Co-Cr } \\
\text { systems }\end{array}$ & 3.6325 & 39.5 & 3.5480 & 78.3 & 3.5935 & 120.5 & --- & --- \\
\hline $\begin{array}{l}\text { Fe-Ni-Co-Cr- } \\
\text { Mn systems }\end{array}$ & 3.6251 & 57.5 & 3.5501 & 76.6 & 3.5947 & 103.5 & 3.6954 & 80.8 \\
\hline
\end{tabular}




\section{Figure Captions}

Figure 1 Candidate deformation mechanisms for high-entropy and equiatomic solidsolution alloys. (a) The rate-determining deformation process in a BCC lattice involves the kink-pair on a gliding screw dislocation. Due to the lattice mismatch and distortion (schematic illustration based on $[15,16]$ ), it is anticipated that local kinks may not be well defined in equiatomic alloys. (b) The classic solution strengthening mechanisms: Fleischer model involves strong pinning of dislocations by solute atoms on the gliding plane, while Labusch model is based weak pinning by "stress centers", i.e., solute atoms all around the space. Fleischer model works for dilute solution, while Labusch model is applicable to concentrated solid solutions.

Figure 2 Engineering stress-strain curves for a family of equiatomic solid-solution alloys at two temperatures, $293 \mathrm{~K}$ and $77 \mathrm{~K}$, with four orders of magnitude change of the applied strain rate. Same color codes are used in these plots. (a) FeNiCoCrMn, (b) FeNiCoCr, (c) FeNiCo, (d) NiCoCr, (e) FeNi, and (f) NiCo.

Figure 3 Plots of yield stress versus strain rate for FeNiCoCrMn, FeNiCoCr, FeNiCo, NiCoCr, FeNi, and NiCo alloys, and Ni polycrystal at (a) room temperature, 293 $\mathrm{K}$, and (b) liquid nitrogen temperature, $77 \mathrm{~K}$. All materials have roughly the same grain size of $100 \sim 110 \mu \mathrm{m}$.

Figure 4 To determine the strain rate sensitivity, the Hall-Petch effect from the grainboundary strengthening must be removed. (a) Fitting to $k / \sqrt{d}$ in Eq. (3) for FeNiCoCr equiatomic alloy shows little change of the slope except at the high

temperature. Data are taken from [13]. (b) The intrinsic strength, $\sigma_{Y}^{\text {intrinsic }}(T, \dot{\varepsilon})$, as obtained from data in Fig. 3 and the Hall-Petch slope in Fig. 4(a), is plotted against the strain rate and temperature for $\mathrm{FeNiCoCr}$ equiatomic alloys at a given grain size of 100 110 $\mu \mathrm{m}$. The straight lines are fitting curves to determine the strain-rate-sensitivity exponent, $m$, in Table 3.

Figure 5 Strain-rate jump tests at strain levels of about 5\%, 15\%, and $25 \%$ for FeNiCoCrMn, FeNiCoCr, FeNiCo, NiCoCr, FeNi, and NiCo alloys, and FCC Ni and BCC Ta polycrystals for comparison purpose. (a) Strain rate jumps from $10^{-3}$ to $10^{-1} \mathrm{~s}^{-1}$ at $293 \mathrm{~K}$. (b) Strain rate jumps from $10^{-3}$ to $10^{-1} \mathrm{~s}^{-1}$ at $77 \mathrm{~K}$. (c) Strain 
rate jumps from $10^{-5}$ to $10^{-3} \mathrm{~s}^{-1}$ at $293 \mathrm{~K}$. These data are used to obtain the activation volume in Table 3.

Figure 6 (a) Yield stress versus temperature for a total of 10 equiatomic alloys and $\mathrm{Ni}$ polycrystal. Data are taken from [13]. (b) The temperature-dependence of $\sigma_{Y}^{\text {intrinsic }}(T, \dot{\varepsilon})$ is analyzed by excluding the Hall-Petch effect an example given for the FeNiCrCo alloy.

Figure 7 The Labusch strengthening factor in Eq. (11) as a function of $\alpha$. (a) $L_{(N-1) \rightarrow N}$, and (b) $L_{1 \rightarrow N}$.

Figure 8 (a) From the measurements of $\sigma_{Y}(T, \dot{\varepsilon})$ in Figs. 3 and 6(a) and the removal of Hall-Petch effects in Figs. 4 and 6(b), the athermal strengthening effect, $\Delta \sigma_{Y}^{\text {intrinsic }}(T \rightarrow 0)$, is compiled for various alloy pairs, $M \rightarrow N$. (b) The Labusch strengthening factor in Eq. (11) for these alloy pairs based on the lattice and modulus mismatches. The general qualitative agreement between these two rows suggest of the validity of Labusch model in predicting the strengthening effect in equiatomic solid-solution alloys.

Figure 9 Proposed thermal activation processes in equiatomic alloys. (a) Long-range bowing with large $\Delta V^{*}$ (e.g., $\sim 80 b^{3}$ at $77 \mathrm{~K}$ and $\sim 300 b^{3}$ at $293 \mathrm{~K}$ for NiCo). (b) Synergy between long-range and short-range effects with low $\Delta V^{*}$ (.e.g, $\sim 15 b^{3}$ at $77 \mathrm{~K}$ and $\sim 50 b^{3}$ at $293 \mathrm{~K}$ for $\left.\mathrm{NiCoCr}\right)$. 
(a)

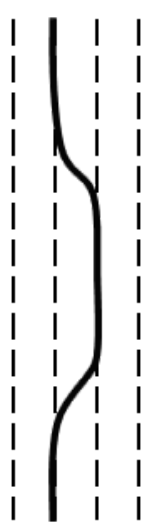

Kink-pair on a moving dislocation

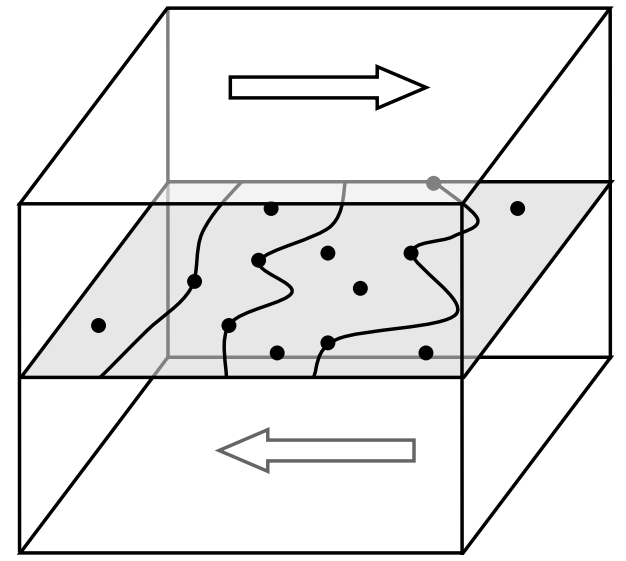

Fleischer model: strong pinning

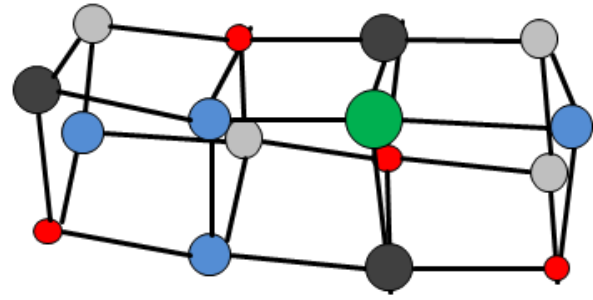

Local kinks in distorted lattices

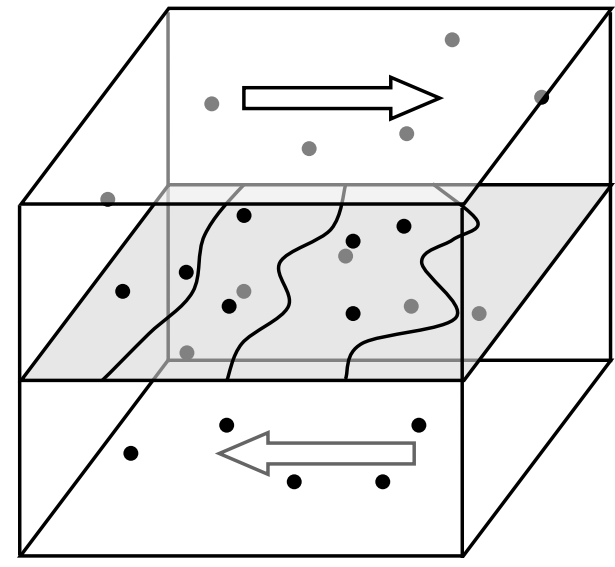

Labusch model: weak pinning

Figure 1 

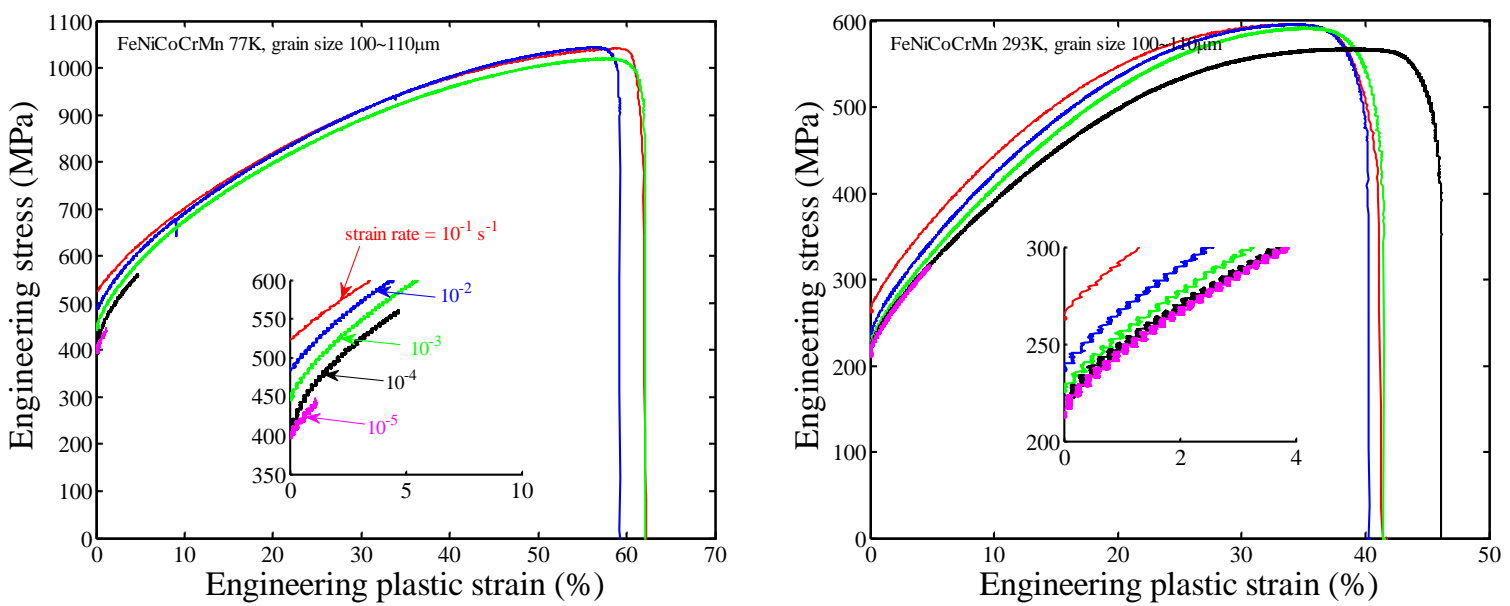

(a)
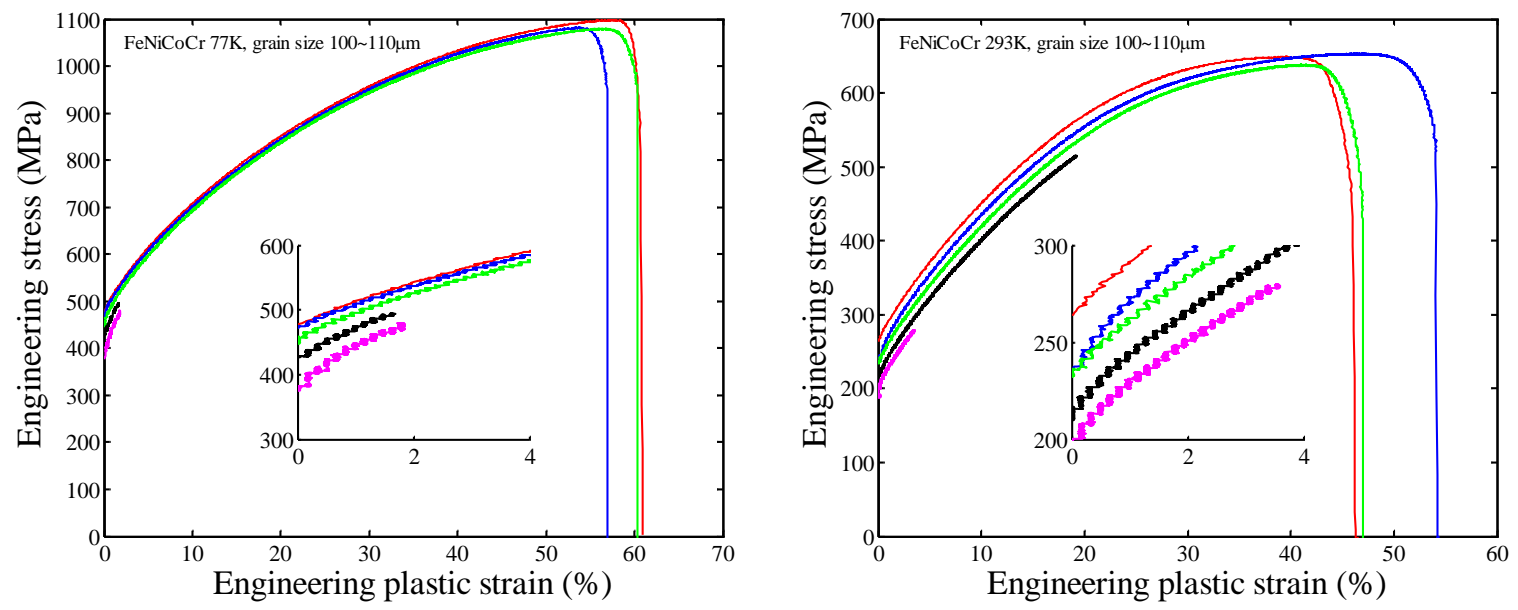

(b)
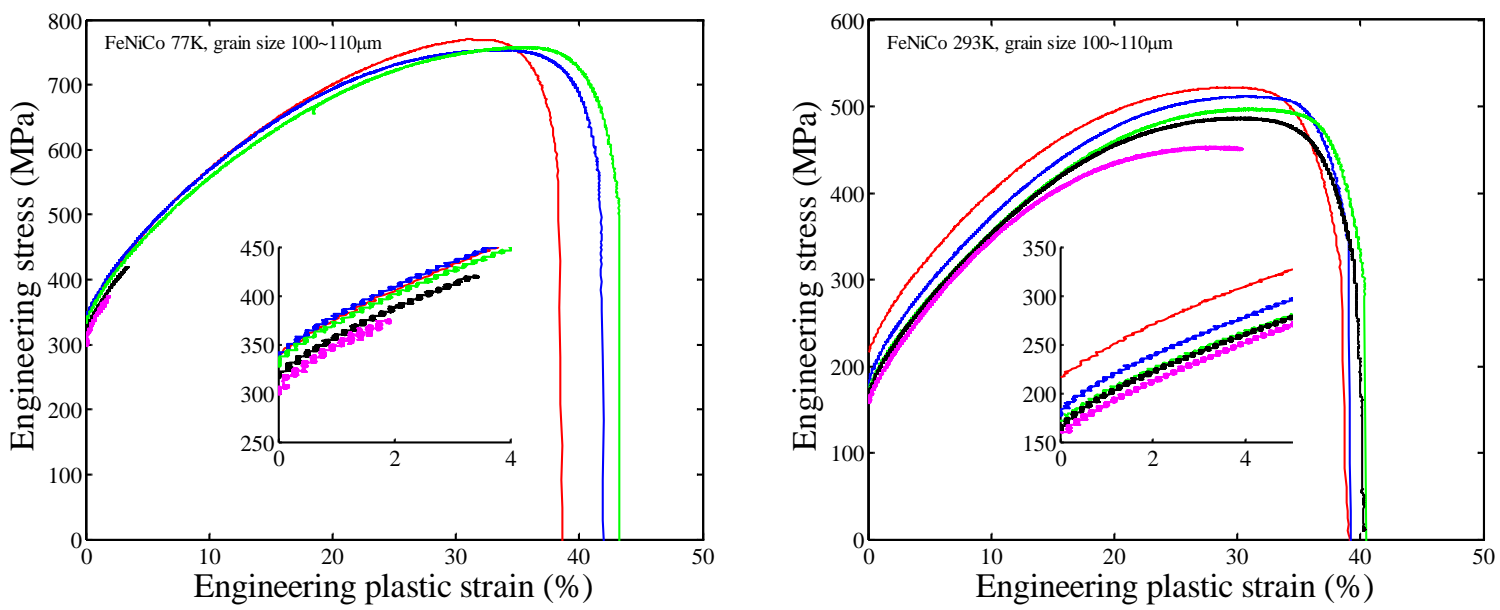

(c)

Figure 2 
(d)
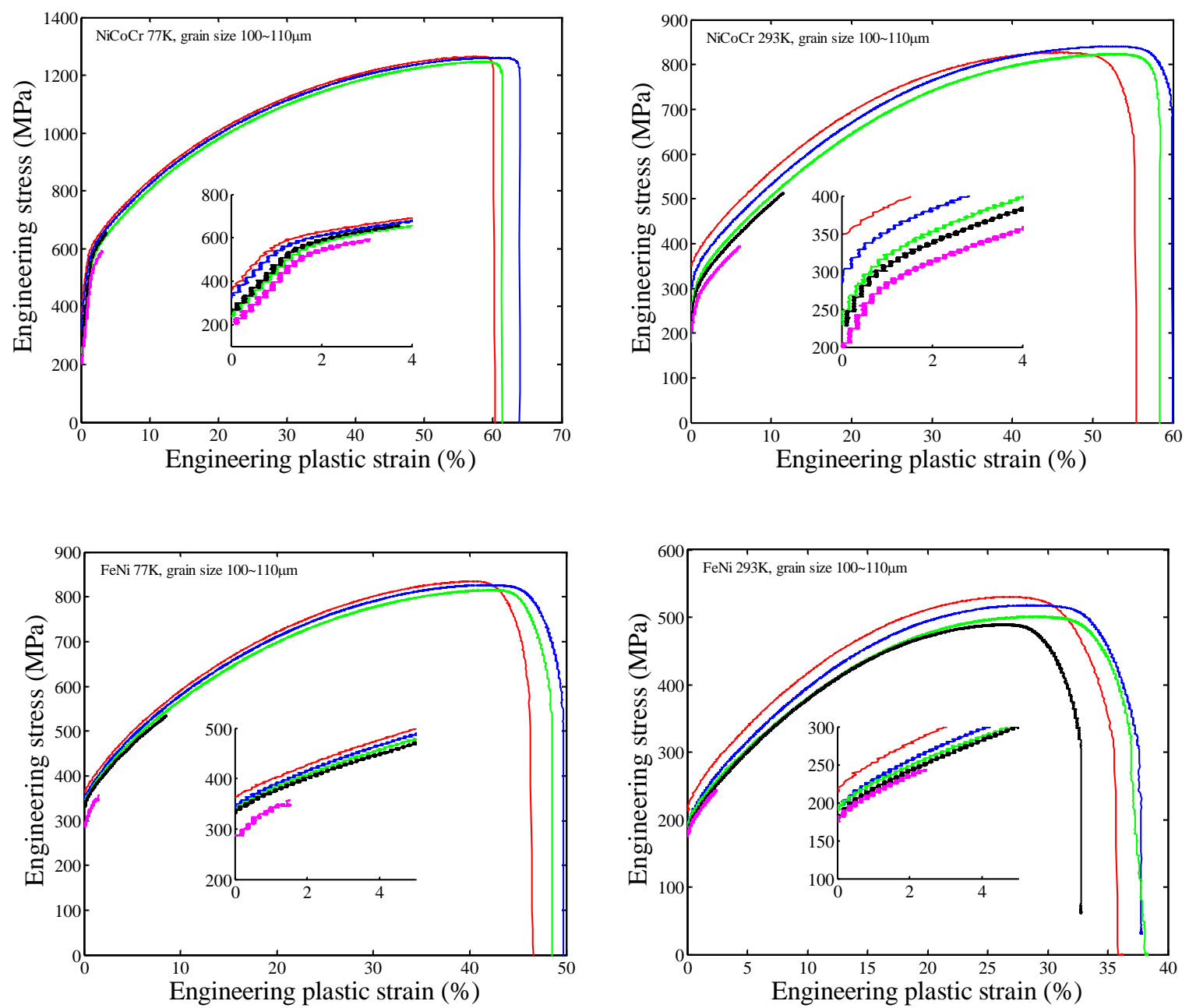

(e)
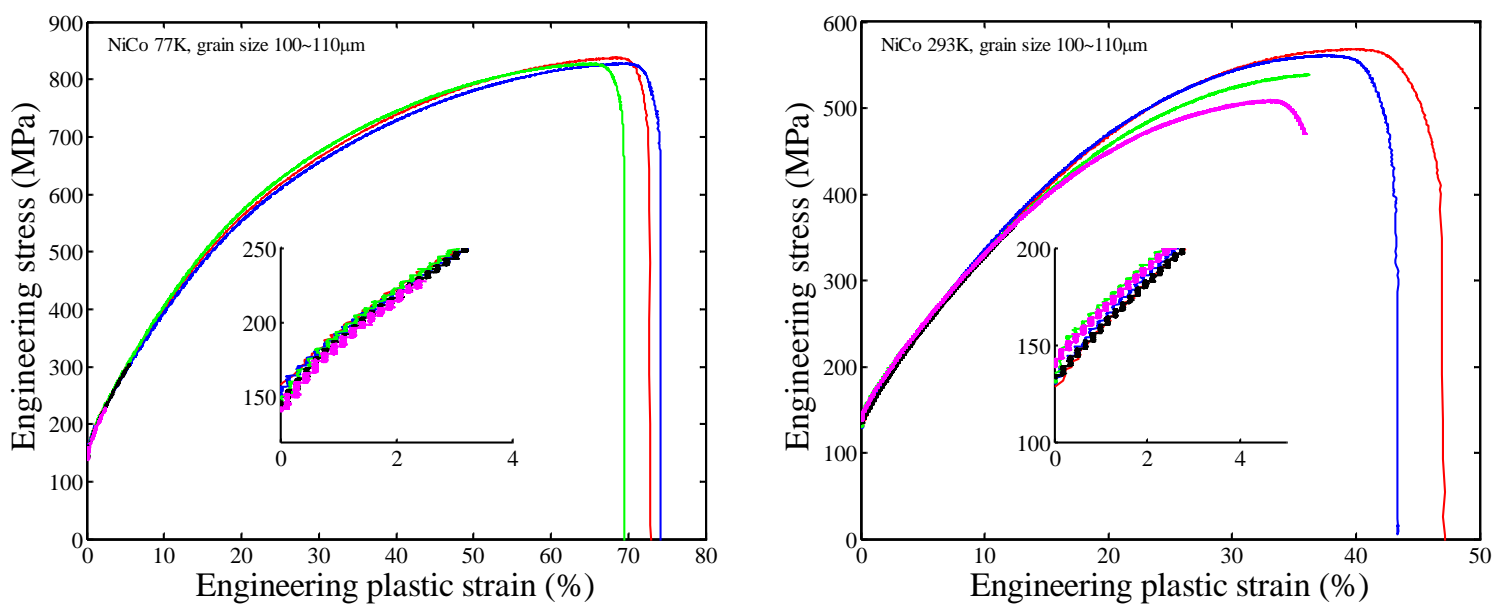

(f)

Figure 2 - cont'd 

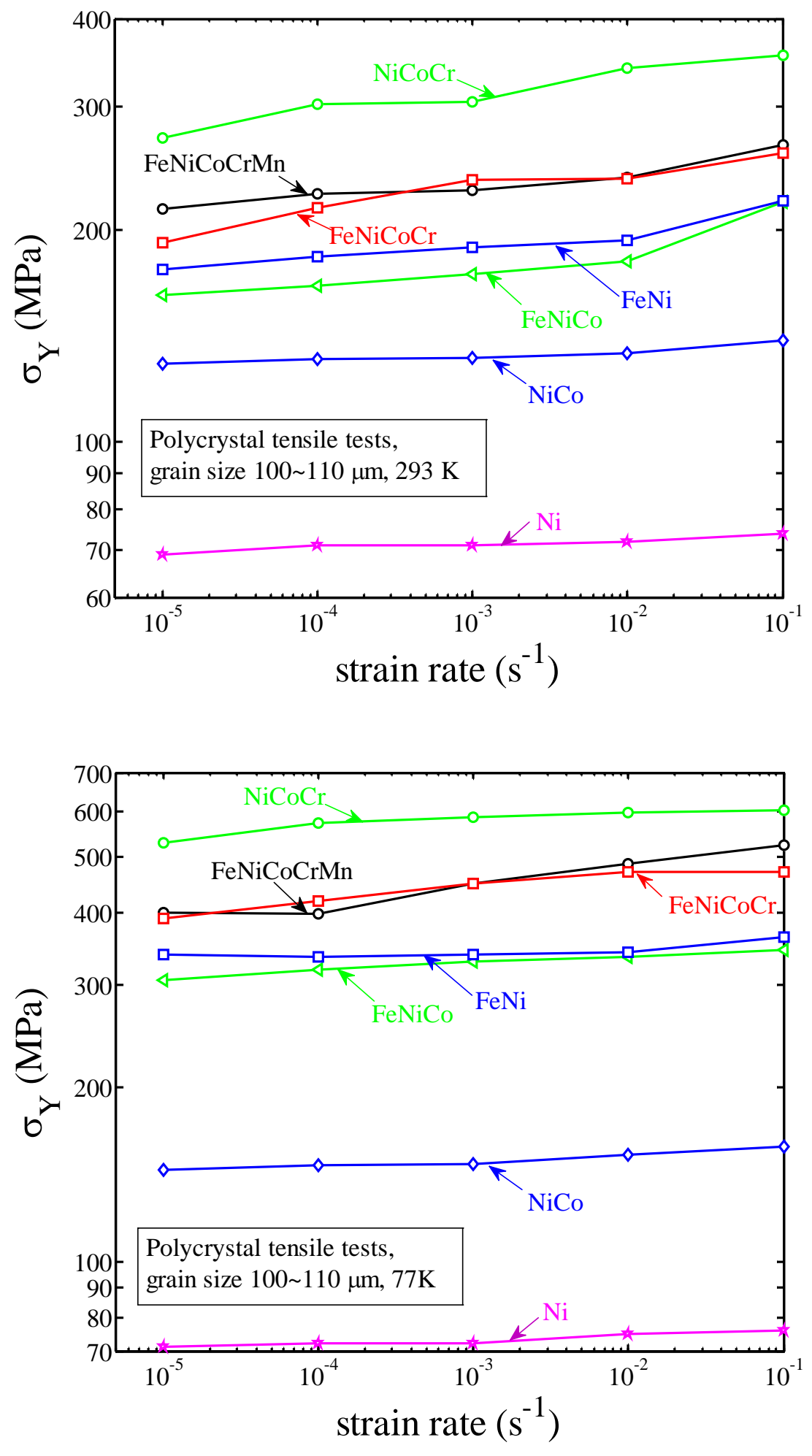

Figure 3 


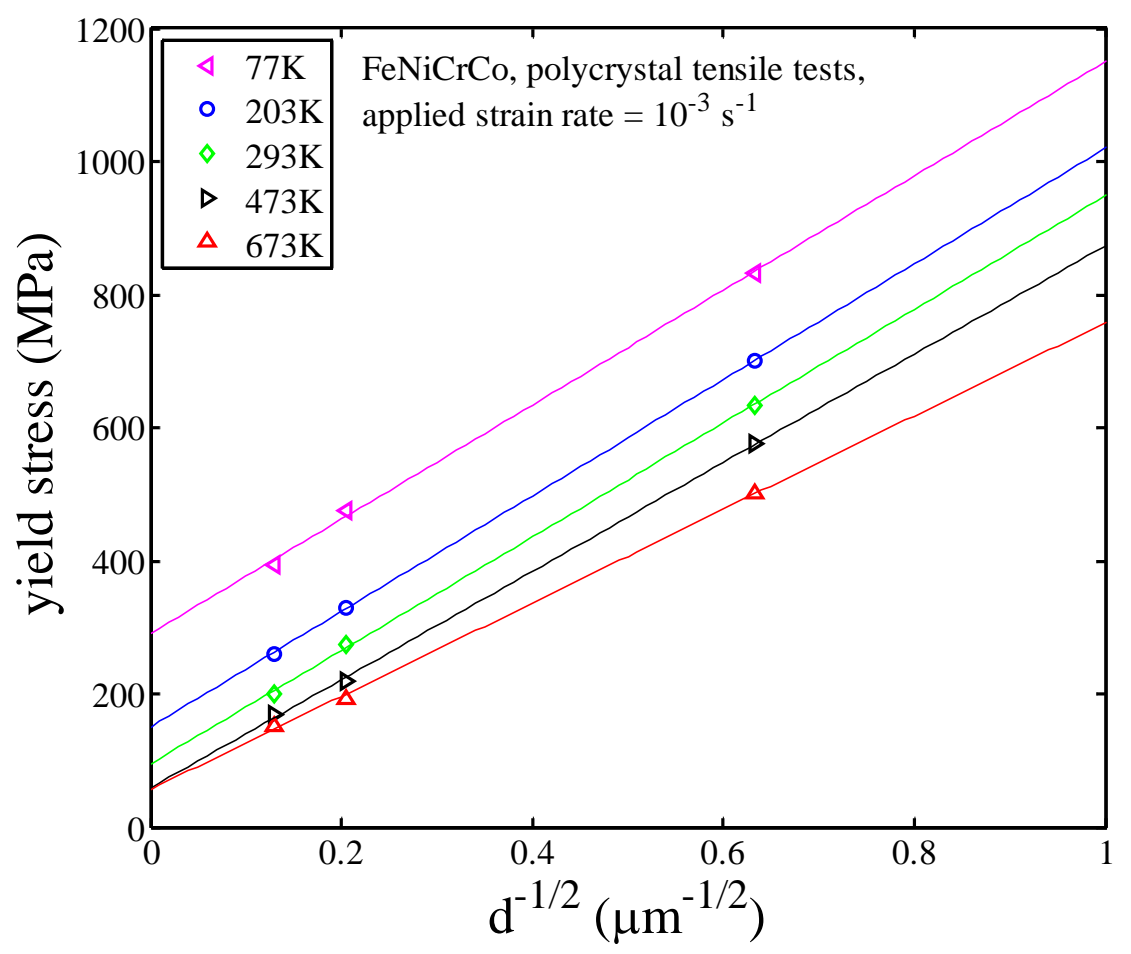

(a)

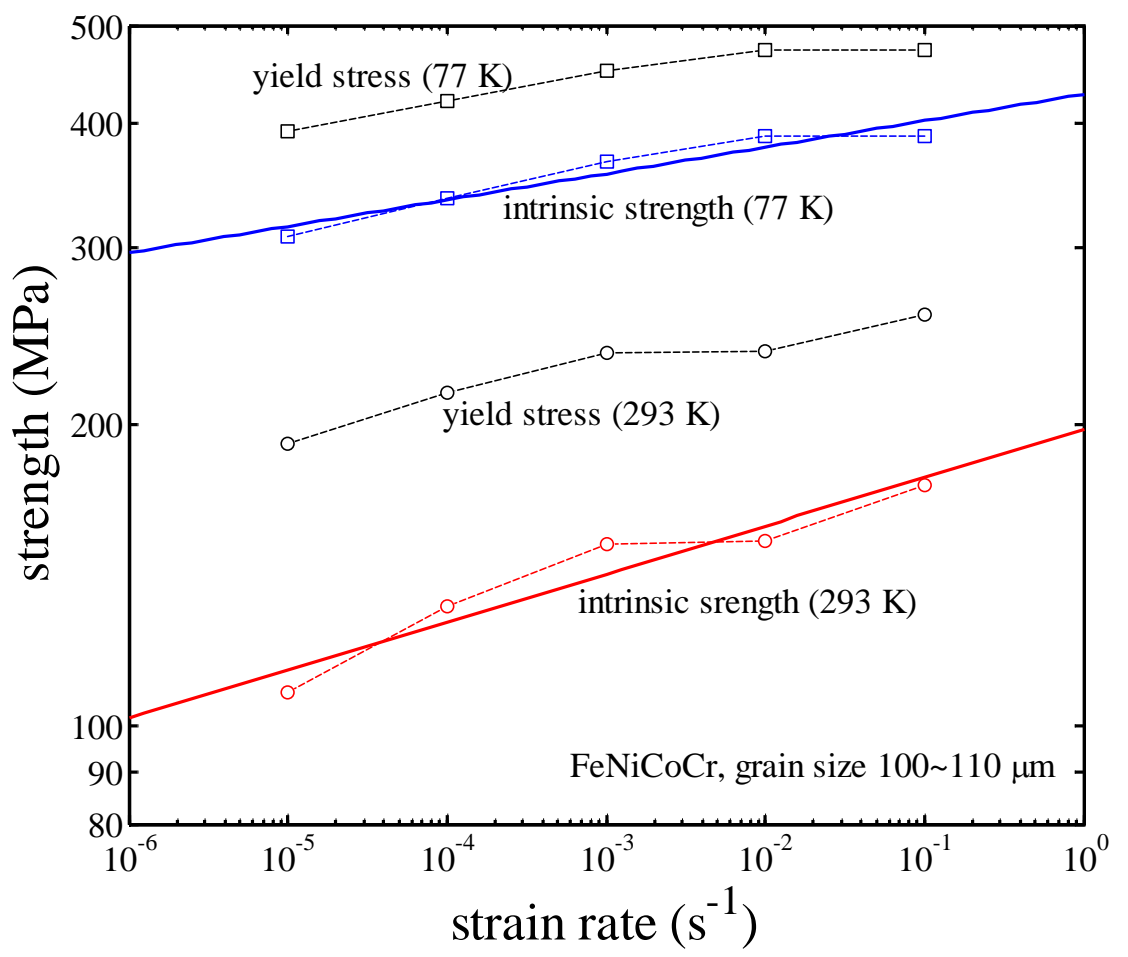

(b)

Figure 4 
(a)
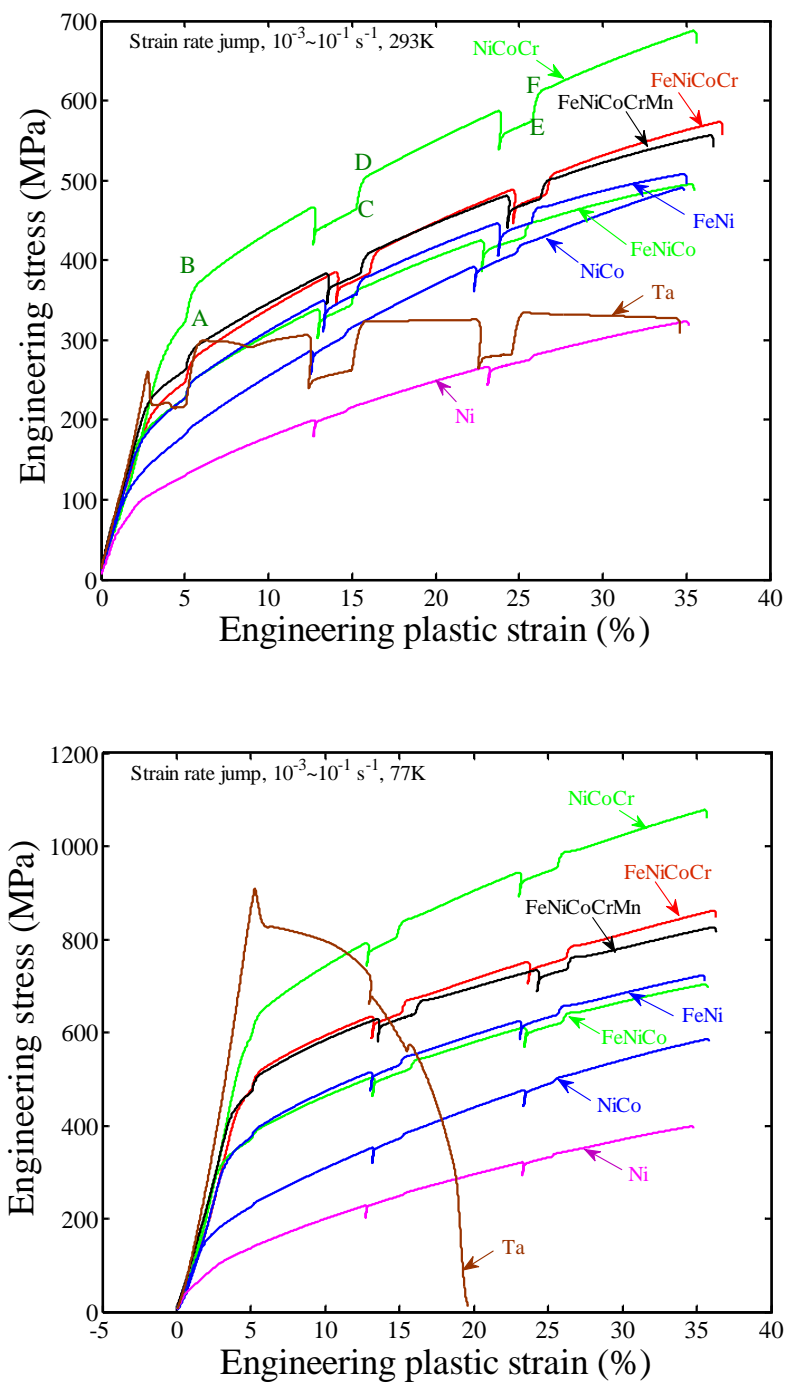

(b)

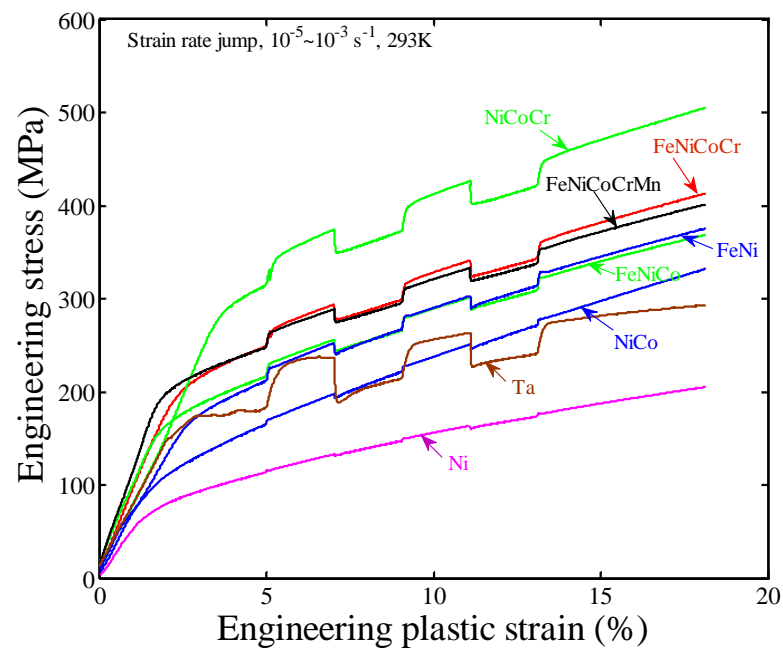

(c)

Figure 5 


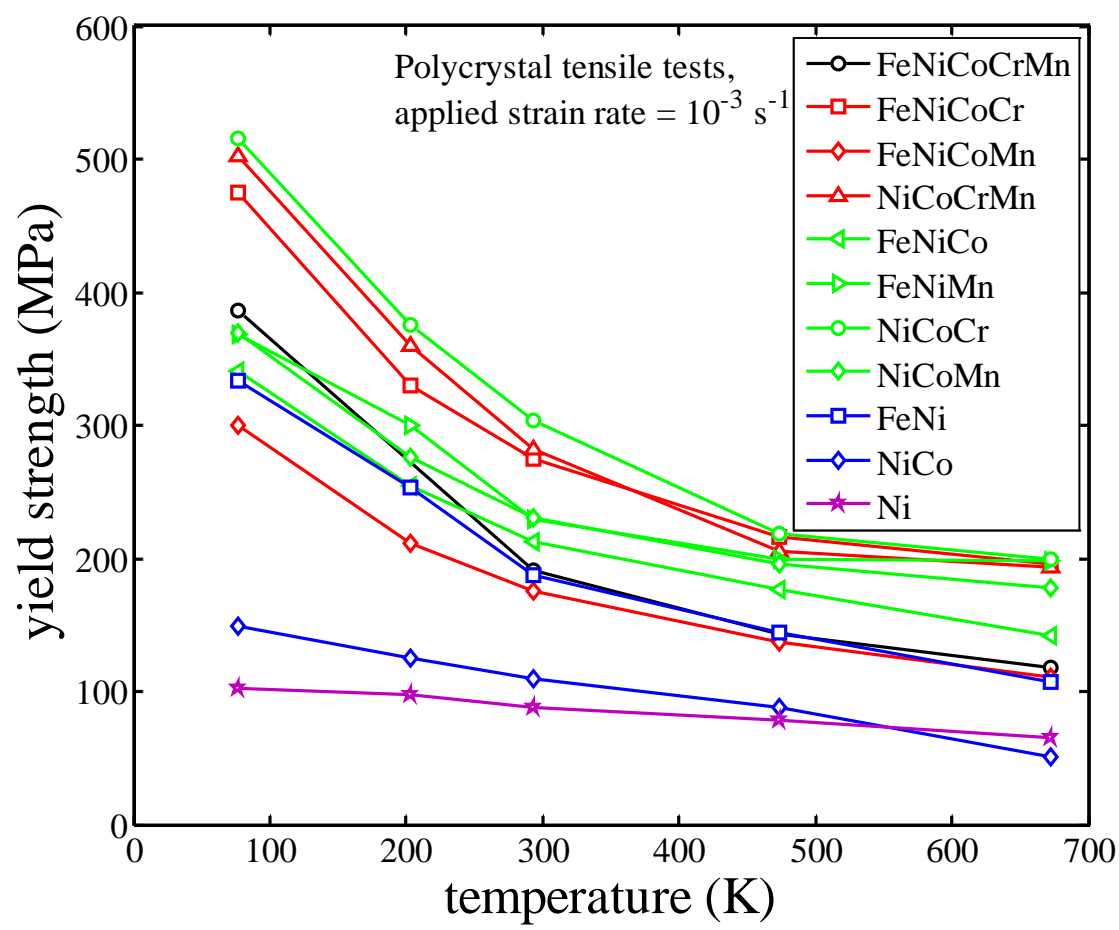

(a)

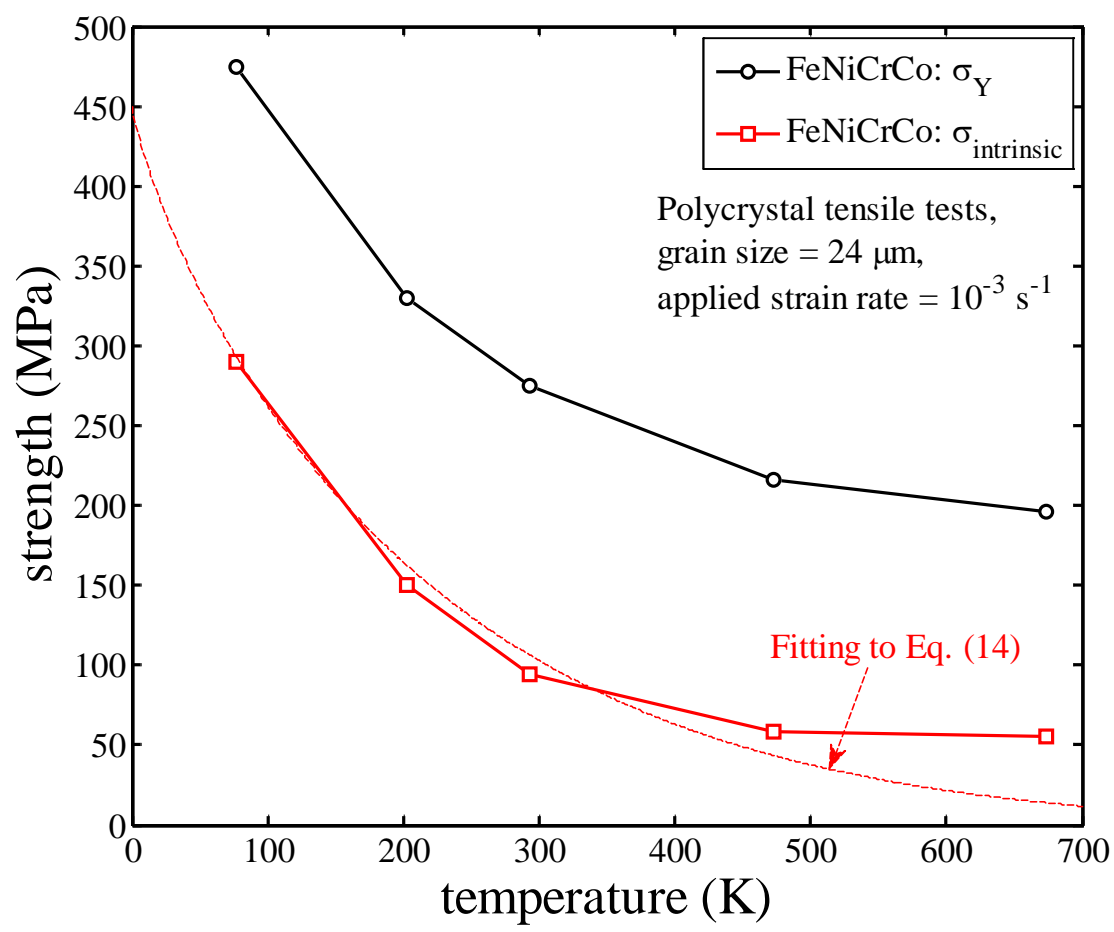

(b)

Figure 6 


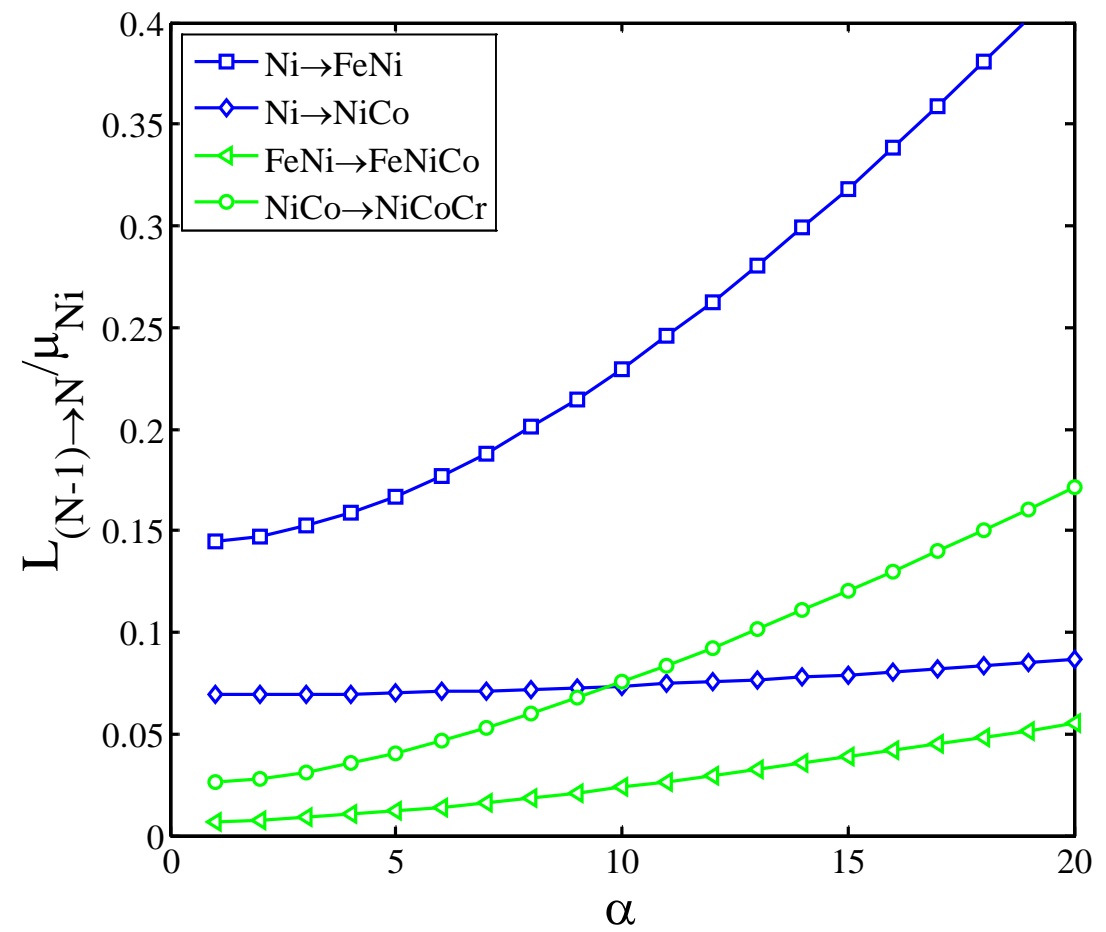

(a)

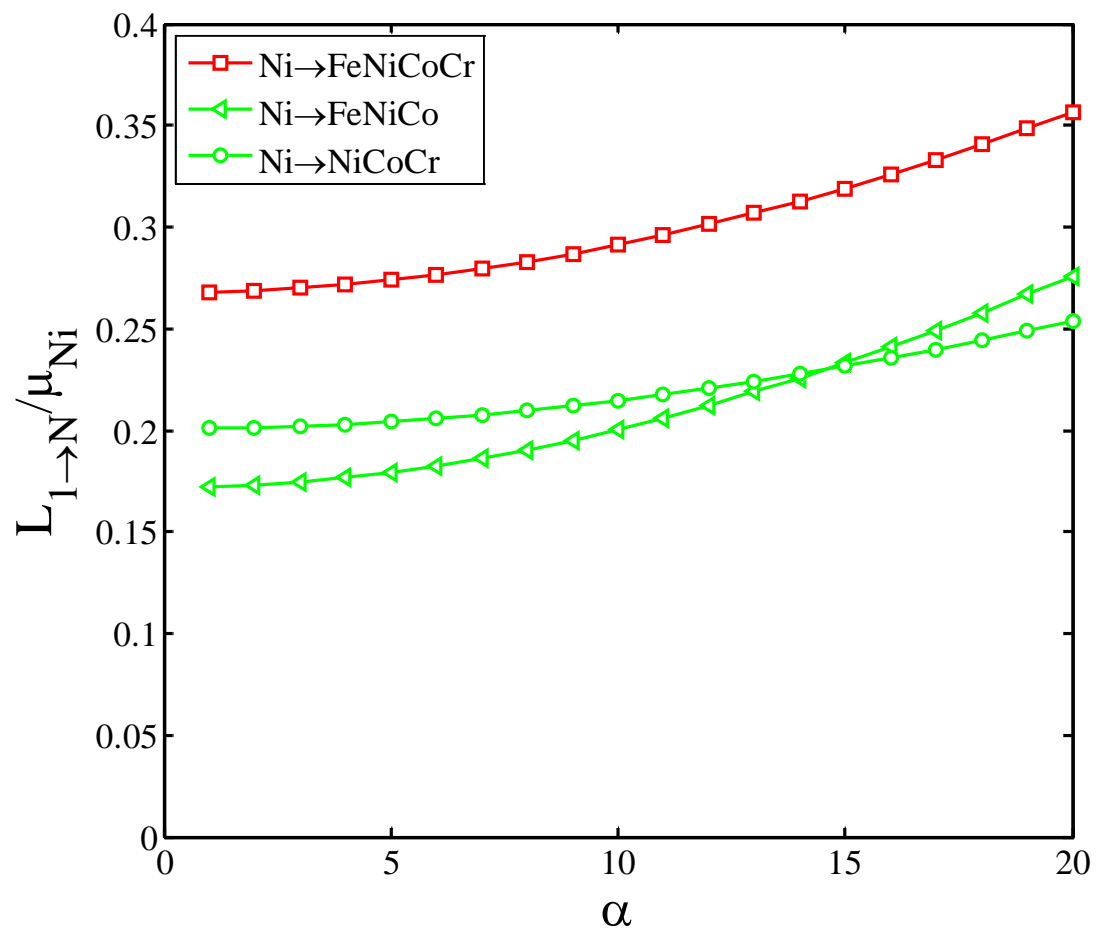

(b)

Figure 7 

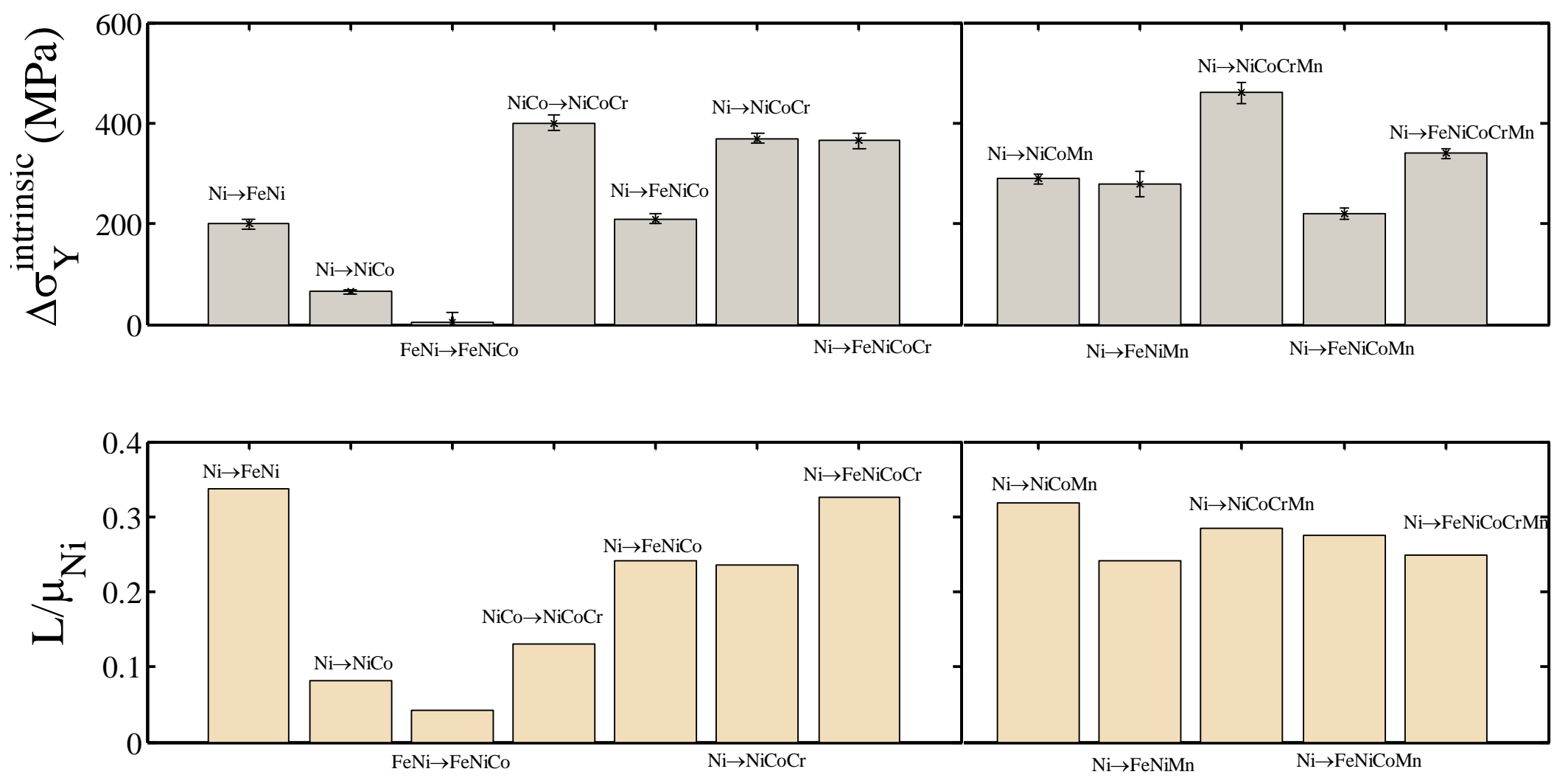

Figure 8 
(a)
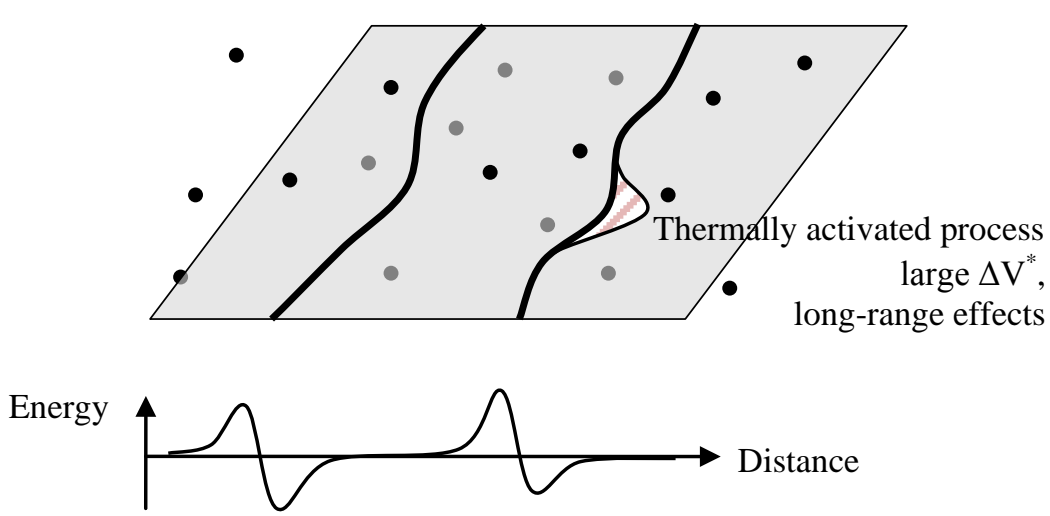

(b)

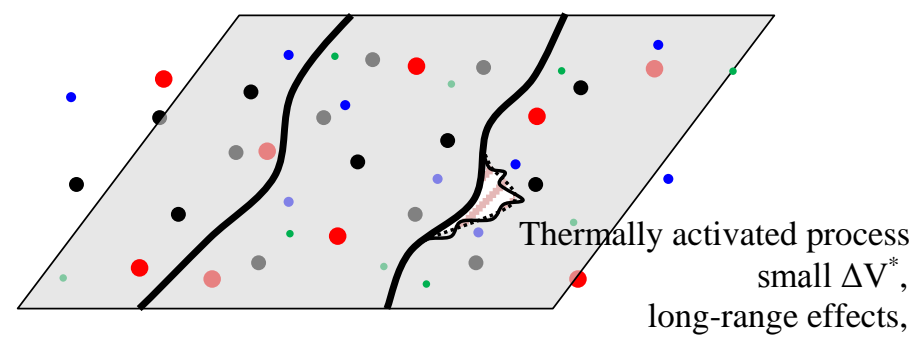
long-range effects,
\& short-range effects

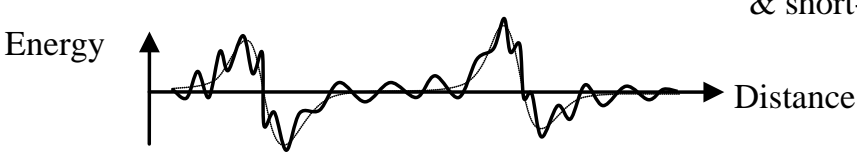

Figure 9 
- Mechanical properties with varying temperature and strain rate for a family of equiatomic quinary, quaternary, ternary, and binary, face-center-cubic-structured, single phase solidsolution alloys.

- Activation volumes are found to range from 10 to 1000 times the cubic power of Burgers vector.

- Labusch-type solution strengthening model qualitatively works for all these alloys.

(a)
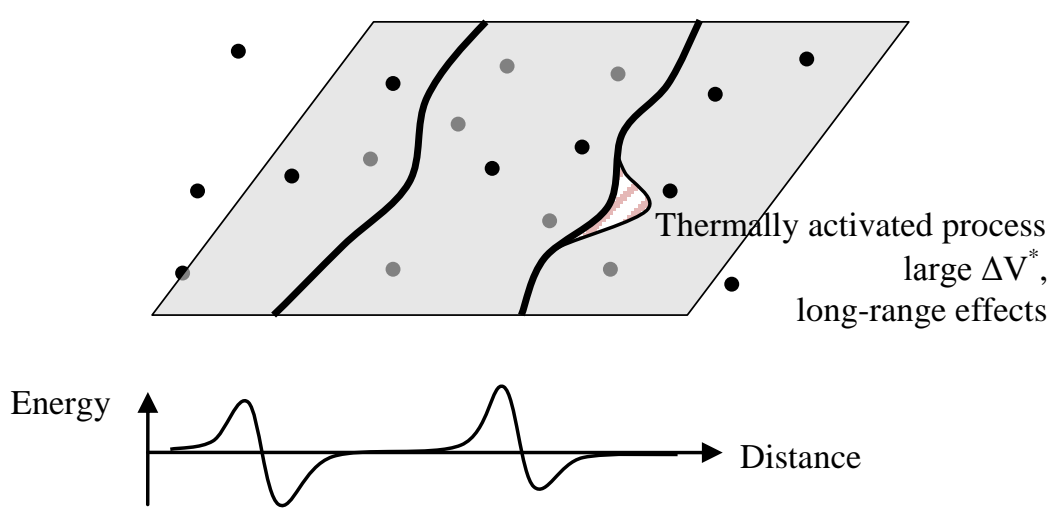

(b)
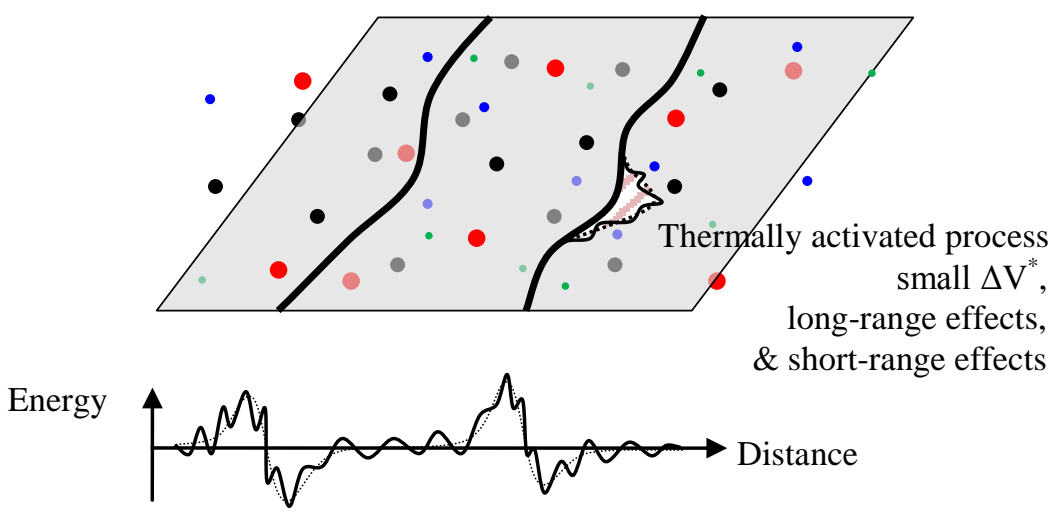